NBER WORKING PAPER SERIES

\title{
LIQUIDITY RISK OF CORPORATE BOND RETURNS: \\ A CONDITIONAL APPROACH
}

\author{
Viral V. Acharya \\ Yakov Amihud \\ Sreedhar T. Bharath \\ Working Paper 16394 \\ http://www.nber.org/papers/w16394
}

\author{
NATIONAL BUREAU OF ECONOMIC RESEARCH \\ 1050 Massachusetts Avenue \\ Cambridge, MA 02138 \\ September 2010 \\ Revised August 2014
}

Published in the Journal of Financial Economics 110(2), 2013, pp. 358-386. We thank an anonymous referee for useful comments. We thank Jason Sturgess and Yili Zhang for diligent research assistance. We are grateful to Banque de France grant for this study, and to Ruslan Goyenko for sharing with us his illiquidity series for the US treasuries. We are grateful for comments from Mark Seasholes and seminar participants at Moody's KMV Annual Credit Risk conference (2007) hosted at NYU Stern, IRC risk management conference in Florence (2008), Arizona State University, Hong Kong University of Science and Technology, McGill, Tel Aviv University, University of Notre Dame, Barclays Global Investors (London), Southern Methodist University, Nanyang Technological University of Singapore, Penn State University, University of Houston, University of Texas at Dallas, University of Virginia (Darden), and University of Toronto (Rotman). This paper won the 2012 Crowell Memorial Prize (second place). All errors remain our own. The views expressed herein are those of the authors and do not necessarily reflect the views of the National Bureau of Economic Research.

NBER working papers are circulated for discussion and comment purposes. They have not been peerreviewed or been subject to the review by the NBER Board of Directors that accompanies official NBER publications.

(C) 2010 by Viral V. Acharya, Yakov Amihud, and Sreedhar T. Bharath. All rights reserved. Short sections of text, not to exceed two paragraphs, may be quoted without explicit permission provided that full credit, including $(\mathcal{C}$ notice, is given to the source. 
Liquidity Risk of Corporate Bond Returns: A Conditional Approach

Viral V. Acharya, Yakov Amihud, and Sreedhar T. Bharath

NBER Working Paper No. 16394

September 2010, Revised August 2014

JEL No. G12,G13,G32,G33

\begin{abstract}
$\underline{\text { ABSTRACT }}$
We study the exposure of the US corporate bond returns to liquidity shocks of stocks and Treasury bonds over the period 1973 - 2007 in a regime - switching model. In one regime, liquidity shocks have mostly insignificant effects on bond prices, whereas in another regime, a rise in illiquidity produces significant but conflicting effects: Prices of investment-grade bonds rise while prices of speculative-grade (junk) bonds fall substantially (relative to the market). Relating the probability of these regimes to macroeconomic conditions we find that the second regime can be predicted by economic conditions that are characterized as "stress." These effects, which are robust to controlling for other systematic risks (term and default), suggest the existence of time-varying liquidity risk of corporate bond returns conditional on episodes of flight to liquidity. Our model can predict the out-of-sample bond returns for the stress years 2008 - 2009. We find a similar pattern for stocks classified by high or low book-tomarket ratio, where again, liquidity shocks play a special role in periods characterized by adverse economic conditions.
\end{abstract}

Viral V. Acharya

Stern School of Business

New York University

44 West 4th Street, Suite 9-84

New York, NY 10012

and CEPR

and also NBER

vacharya@stern.nyu.edu

Yakov Amihud

New York University

Stern School of Business

44 West Fourth Street, Suite 9-190

New York, NY 10012

yamihud@stern.nyu.edu
Sreedhar T. Bharath

Department of Finance

University of Michigan

Room D7606 ER

701 Tappan Street

Ann Arbor, MI 48109-1234

sbharath@asu.edu 


\section{Introduction}

This paper shows that the pricing of liquidity risk in the bond market is conditional on the state of the economy, with liquidity risk becoming more important in times of financial and economic distress. Using a regime-switching model, we find a significant (absolute) increase in the exposure ("beta") of corporate bond returns to liquidity shocks in stocks and Treasury bonds, after controlling for term and default risks. We provide an econometric time-series model that predicts the likelihood of regime in which liquidity matters more for asset pricing, show that the likelihood is greater in times of macroeconomic and financial distress, and use the prediction to generate a conditional forecast of bond returns. We further find that stocks with high book-to-market ratio, which reflects persistent distressed performance and lower liquidity, also exhibit an increase in their (absolute) liquidity betas in times of economic distress.

Liquidity shocks affect realized returns because expected liquidity affects expected returns (Amihud and Mendelson, 1986, 1991). Given the persistence of illiquidity, a positive illiquidity shock raises future expected illiquidity and expected return which in turn lowers prices. This usually generates a negative liquidity beta. ${ }^{1}$ These relations between illiquidity shocks and returns have been documented for stocks by Amihud (2002), Pastor and Stambaugh (2003), Acharya and Pedersen (2005), and Sadka (2006), and for corporate bonds by de Jong and Driessen (2007), and Lin, Wang, and Wu (2011). This paper contributes to these studies by showing that the impact of liquidity shocks on asset prices is conditional, being significantly stronger in adverse economic times.

The relation between liquidity shocks and adverse economic and financial episodes has been noted by Acharya and Pedersen (2005). ${ }^{2}$ In times of adverse economic and financial conditions, the greater demand for liquidity and the rise in its value reduces asset prices

\footnotetext{
${ }^{1}$ This holds under reasonable assumptions on the asset cashflows; see a formal model in Acharya and Pedersen (2005).

${ }^{2}$ Over the period 1963 to 1999, Acharya and Pedersen (2005) identify these shocks to be 5/1970 (Penn Central commercial paper crisis), 11/1973 (oil crisis), 10/1987 (stock market crash), 8/1990 (Iraqi invasion of Kuwait), 4 - 12/1997 (Asian crisis), and 6 - 10/1998 (Russian default, LTCM crisis).
} 
by more than usual, and this applies particularly for the less liquid assets. Yet, these episodes may be coupled by a flight to liquidity, by which securities with higher liquidity become relatively more valuable. Then, unexpected rise in illiquidity may raise, rather than depress, the prices of assets that provide greater liquidity in adverse economic times relative to the prices of less liquid assets. This is indeed what we find for investment-grade (IG) corporate bonds, which are known to be more liquid than speculative (junk) bonds. Analogously, we also find that in times of economic distress, the effect of adverse liquidity shocks is positive (relative to the market) for stocks with low book-to-market ratio, which have stronger sustained profitability and higher liquidity, whereas the effect is negative for stocks with high book-to-market ratio.

Formally, we estimate a regression model of bond returns on four pricing factors - term spread returns, default spread returns (or the bond market excess returns), and liquidity shocks on stocks and Treasury bonds. We study the association between changes in corporate bond price shocks and changes in the illiquidity of stocks and Treasury bonds. We show that this response varies over time, switching between two regimes which we characterize as "normal" and "stress." Employing Hamilton's (1989) methodology, we first identify statistically the two regimes between which there are variations in the liquidity betas as well as the betas of the term risk and default risk. We then show that these two regimes can be predicted by macroeconomic and financial variables. The regime which we call "stress" is associated with adverse macroeconomic conditions such as recessed economic activity and adverse financial market conditions such as negative stock market returns, heightened volatility, and shrinking balance-sheets of financial intermediaries.

Employing our economic prediction model of being in the normal or in the stress regime, we provide an out-of-sample forecast of corporate bond returns for the years 2008 - 2009. In regressions of monthly realized returns on predicted returns that are conditional on the pricing factors, $R^{2}$ is $76 \%$ and $77 \%$ for junk and IG bonds, respectively, and the coefficients indicate unbiased prediction: the slope coefficients are close to one and the intercepts are 
close to zero. As shown in Fig. 5, the predicted return does a reasonable job at predicting the returns of March 2008 (Bear Stearns' collapse) and September to December 2008 (Lehman Brothers' collapse and the post-Lehman phase). In another out-of-sample test for the second half of the sample, ${ }^{3}$ we again obtain that the prediction has significant power with an accuracy of over $88 \%$.

Importantly, we find that in the stress regime, the sign of liquidity betas is quite the opposite for IG and junk bonds. Junk bond returns respond negatively to illiquidity shocks while IG bond returns respond in a positive and significant way (these effects are relative to the effect of liquidity shocks on the bond market excess return). In this regime, there is a large significant difference in the return-illiquidity shock relation between IG and junk bonds, whereas in the normal regime, this difference is smaller and less significant. This pattern is robust to controlling for maturity and default risk. The evidence thus suggests that in the stress regime there is a "flight to liquidity" wherein investors prefer (or price more favorably) more liquid assets such as IG bonds rather than the less liquid junk bonds. To further confirm this flight to liquidity, we show that Treasury bill yields fall relative to the federal funds rate during the stress regime and become more sensitive to bond liquidity shocks.

This analysis is extended to stocks sorted on their book-to-market ratio. Fama and French (1995) show that the profitability of stocks with high book-to-market ratio is persistently distressed, with the opposite holding for stocks with low book-to-market ratio. And, Fang, Noe, and Tice (2009) show that stocks with higher book-to-market ratio are associated with lower liquidity, because lower liquidity depresses stock value. Thus, stocks with higher book-to-market ratio are similar to junk bonds in the sense that they have greater economic distress and lower liquidity. Similar to our findings for corporate bonds, we identify statistically two regimes which differ mainly in the effect of stock liquidity shocks on the excess returns

\footnotetext{
${ }^{3}$ For each month, we progressively estimate the best econometric fit using macroeconomic and financial-market variables that explain the model-implied probability of being in the stress regime until the previous month, and use it to predict the statistically identified probability of being in the stress regime in that month obtained from the time-series regressions of bond returns on the pricing factors.
} 
of stock portfolios constructed based on their book-to-market ratio. Again, we find that the probability of being in these regimes is predictable by the same macroeconomic and financial market variables that predict the liquidity risk regimes for corporate bond returns. The probability of being in the regime where stocks - particularly those with high book-to-market ratio-have greater stock liquidity risk is significantly related to market conditions that indicate economic and financial stress.

Finally, we directly relate the returns on stocks sorted by their book-to-market ratio to returns on stocks sorted on their likelihood of default, using Altman's Zscore as modified by Hillegeist et al. (2004). We form portfolios of high and low default-risk stocks. Then we relate the return on high-minus-low book-to-market stocks (HMLBM) to returns on high-minus-low default-risk stocks (HMLDEF), adding the two liquidity shock variables. This enables us to test the effect of liquidity risk after controlling for default risk, captured by HMLDEF. We obtain that the control for default risk completely accounts for the well-known HMLBM premium, while the risk of stock liquidity shocks is highly significant in times of adverse economic conditions but not otherwise. The time periods in which the liquidity risk is significant are strongly related to the time periods associated with adverse economic conditions for liquidity risk in returns on bonds and stocks. This further substantiates our proposition that liquidity risk is conditional on the state of the economy.

In summary, our conditional approach to modeling the liquidity risk of securities exposed to default risk and distressed performance yields new explanations for understanding asset prices. A large body of recent literature (e.g., Brunnermeier and Pedersen, 2009; He and Krishnamurthy, 2012; Acharya and Viswanathan, 2011, among others discussed in Section 4), has stressed that financial intermediaries reduce liquidity provision in response to adverse liquidity shocks, especially in times of economic and financial stress, when they exhibit a flight to liquid assets. The results in our paper are consistent with some of the theoretical predictions.

(a) There is a conditional response and differential response (between junk and IG bonds, 
or between stocks with low and high book-to-market ratios) of default-risky securities to market-wide liquidity shocks;

(b) There is a phenomenon of "flight to liquidity" that is separate from flight to quality;

(c) There is a highly significant relation between the probability of the distress regime, during which liquidity shocks have the greatest impact, and dealers' (or financial intermediaries') inventories and their interaction with market volatility.

Our analysis shows that default exposure as regimes change is really separate from exposure to illiquidity shocks. Therefore, the exposure that otherwise would have been attributed to default risk is in fact exposure to liquidity risk.

We also provide a new methodological procedure to study episodic changes in exposure of securities prices and their economic and financial causes. We begin with a statistical first-step to identify significant "regime" shifts in exposures in a statistical first-step and then, in a second-step analysis, we relate the probability of being in regimes to macroeconomic and financial conditions. The second step enables an unconstrained examination of the factors affecting the regimes, which is more flexible and broad than in methods that incorporate predetermined factors into the one-step regime-switching analysis. This methodology could be used in future work for conditional analysis of other factor exposures of asset prices.

The paper proceeds as follows. Section 2 describes the data we employ. Sections 3 and 4 present results for our unconditional and conditional liquidity risk tests, respectively. Section 4 also reports results of the out-of-sample tests. Section 5 presents results on stock portfolios constructed according to their book-to-market ratio. Section 7 discusses additional related literature. Section 8 offers final conclusions.

\section{Data}

Our bond data are extracted from the Lehman Brothers Fixed Income Database distributed by Warga (1998) and supplemented by the Merrill Lynch corporate bond index database used by Schaefer and Strebulaev (2008). We follow closely the data extraction methodology 
outlined by Bharath and Shumway (2008) for the Warga (1998) database. The Warga (1998) database contains monthly price, accrued interest, and return data on all corporate and government bonds over the period January 1971 - March 1997. We use the data from the 1973 - 1997 period when coverage became widespread. This is the database used by Elton et al. (2001) to explain the yield spread on corporate bonds, and by Gebhardt et al. (2005) in their study of the cross-section of bond returns. In addition, the database contains descriptive data on bonds, including coupons, ratings, and callability.

This study uses a subset of the data in the Warga database by employing several selection criteria. First, we include only bonds that were priced by traders or dealers and eliminate bonds that were matrix-priced. ${ }^{4}$ This rule is similar to that behind the CRSP government bond file, which is the standard academic source of government bond data. Next, we eliminate all bonds with special features that would result in them being priced differently. This means that we eliminate all bonds with options (e.g., callable bonds or bonds with a sinking fund), with floating rates, with an odd frequency of coupon payments, and inflation-indexed bonds. In addition, we eliminate all bonds not included in the Lehman Brothers bond indexes, because researchers in charge of the database at Lehman Brothers indicated that the care in preparing the data was much less for bonds not included in their indexes. This also results in eliminating data for all bonds with a maturity of less than one year.

These data are supplemented by data on monthly prices of corporate bonds that are included either in the Merrill Lynch Corporate Master Index or in the Merrill Lynch Corporate High Yield Index used by Schaefer and Strebulaev (2008). These indexes include most rated US publicly issued corporate bonds. The data cover the period from December 1996 to December 2007. The selection criteria used for the Lehman database were also used with the

\footnotetext{
${ }^{4}$ For actively traded bonds, dealers quote a price based on recent trades of the bond. We eliminate bonds for which a dealer did not supply a price because they have prices determined by a rule of thumb relating the characteristics of the bond to dealer-priced bonds. These rules of thumb tend to change very slowly over time and do not respond to changes in market conditions. For matrix prices, all that our analysis uncovers may be the rule used to matrix-price bonds rather than the economic influences at work in the market.
} 
Merrill database. Thus, during the overlapping period between the two databases (December 1996 to March 1997), the constituent bonds in the two databases are nearly identical. In the Lehman database all bonds have missing data in August 1975 and December 1984, and their prices are replaced by interpolated prices. Most bond issues are rated by both S\&P and Moody's and the ratings agree with each other. We eliminate unrated bonds and bonds whose rating by S\&P and Moody's is not the same for the broad letter-based categories.

The monthly corporate bond return as of time $\tau+1, r_{\tau+1}$ is computed as

$$
r_{\tau+1}=\frac{P_{\tau+1}+A I_{\tau+1}+C_{\tau+1}-P_{\tau}-A I_{\tau}}{P_{\tau}+A I_{\tau}} .
$$

$P_{\tau}$ is the quoted price in month $\tau ; A I_{\tau}$ is accrued interest, which is just the coupon payment scaled by the ratio of days since the last payment date to the days between last payment and next payment; and $C_{\tau+1}$ is the semiannual coupon payment (if any) in month $\tau+1$. For the bond return indexes that we use, we value-weight the monthly returns of all eligible bonds in each rating class by the total amount outstanding of each bond. This reduces significantly price errors for particular bonds. In our sample over the period 1973 - 2007, there were on average 2,234 bonds in each month, with a minimum number of 245 and a maximum number of 9,286. The maximum number of months in our sample period is 420 , but data are missing for some rating classes in some months.

\section{ENTER TABLE 1}

Table 1 Panel A reports the summary statistics of the value-weighted returns on corporate bonds aggregated into portfolios by rating classes. The weights are based on face value outstanding and returns are in basis points, denoted bps. As expected, the mean and standard deviation of bond returns are greater for bonds with greater default risk. The monthly mean return on AAA-rated bonds is 67.2 bps with standard deviation of 134.5 bps, and for CCC bonds, the mean and standard deviation are, respectively, 160.3 bps and 332.0 bps. For most of our analysis, we rely on groupings into investment-grade ("IG," BBB-rated 
and above) and high-yield speculative ("junk," below BBB-rated) bonds. For this grouping, we find that the returns on IG and junk bonds are, respectively, 67.6 and $97.6 \mathrm{bps}$ and the respective standard deviations are 127.3 and 177.9 bps.

We follow Fama and French (1993) in using two common factors for corporate bonds, TERM and DEF, which reflect unexpected changes in the term structure of interest rates and in default risk. Fama and French (1993) justify these choices by an Intertemporal CAPM setting in which these two factors are hedging portfolios. ${ }^{5}$ Following Gebhardt et al. (2005), we calculate the factor TERM as the difference in the monthly long-term 30-year government bond return (from Ibbotson Associates) and one-month T-bill returns (from the Center for Research in Security Prices, CRSP), and the factor DEF as the difference between the monthly return on an equally weighted market portfolio of all corporate bonds with at least one year to maturity and the average return on government bonds. The latter is the average returns on one-year and 30-year government bonds because corporate bonds whose returns are used to construct DEF have maturities from one to 30 years. Thus, DEF is the bond market excess return; the equal-weighting better captures the extreme default outcomes each month.

We add to the model two liquidity risk factors which are innovations in the illiquidity on stocks and bonds. The stock illiquidity index is the market's average price-impact measure of Amihud (2002), as modified by Acharya and Pedersen (2005). It is calculated as the equally weighted average of the daily ratio of absolute stock return to its daily dollar volume, and averaged over the days of the month to provide the monthly stock illiquidity measure, using NYSE and Amex stocks. ${ }^{6}$ The bond illiquidity measure is the equally weighted quoted bid-ask spread on on-the-run short maturity Treasuries. ${ }^{7}$ The innovations in the stock (bond)

\footnotetext{
${ }^{5}$ Following the suggestion and results in Gebhardt et al. (2005, footnote 2), we do not include the stock market factor which they found empirically to have almost no explanatory power for corporate bond returns in the presence of default and term risk factors.

${ }^{6}$ To make ILLIQ stationary, the series is modified by the normalization formula due to Pastor and Stambaugh (2003) and Acharya and Pedersen (2005): the ratio of the capitalizations of the market portfolio at the end of month $t-1$ and of the market portfolio at the end of July 1962.

${ }^{7}$ These data are as in Goyenko (2006). We thank Ruslan Goyenko for providing us the data.
} 
indexes are the residuals from an autoregressive model with $\mathrm{AR}(3)(\mathrm{AR}(2))$ specification, with the lag length being selected to ensure that the residuals are serially uncorrelated. ${ }^{8}$ We call the innovations in the stock and bond illiquidity indexes Silliq and Billiq, respectively.

Panel B of Table 1 presents summary statistics on the four factors that we use in this study. The mean risk premium for the default factor (DEF) is 9.5 bps per month with $t=$ 1.72, while the average risk premium for the term factor (TERM) is 17.7 basis points per month, which is insignificantly different from zero. The mean of the two liquidity factors is practically zero. Panel $\mathrm{C}$ of Table 1 shows the pairwise correlations between TERM, DEF, and the two liquidity risk factors. TERM and DEF are highly negatively correlated (correlation $=-0.529)$, whereas the two liquidity risk factors are less correlated with each other $($ correlation $=0.086)$, and they are also not highly correlated with TERM and DEF (the correlations of DEF with Billiq is -0.057 and with Silliq it is -0.153). This helps with a clean interpretation of the liquidity risk effects we identify.

\section{ENTER FIGURES 1-3}

Fig. 1 plots the investment-grade and junk bond returns over time which appear to be more variable during the early 1980s, the early 1990s recession, and late 1990s. Fig. 2 plots the time-series of TERM and DEF. Finally, Fig. 3 plots the standardized bond and stock market illiquidity innovations. The measured innovations in market illiquidity are high during periods that were characterized by liquidity crises, for instance, the oil shock of 1973, the 1979 - 1982 period of high interest rates, the stock market crash of 1987, the 1990 recession, and the 1998 LTCM crisis.

\section{Unconditional liquidity risk of bond returns}

In this section, we first examine as a benchmark the unconditional effect of liquidity factors on corporate bond returns divided into categories by ratings.

\footnotetext{
${ }^{8}$ The estimated AR model coefficients employ the Shaman-Stine (1988) correction for finite sample coefficients. The estimation period of this model coincides with the data period.
} 


\subsection{Methodology and results}

First, we estimate the following time-series specification:

$$
\begin{aligned}
R_{j, t} & =\alpha_{j}+\beta_{j, T} \times T E R M+\beta_{j, D} \times D E F \\
& +\beta_{j, S i} \times \text { Silliq }+\beta_{j, B i} \times \text { Billiq }+\epsilon_{j, t}
\end{aligned}
$$

for $R_{j, t}$ being the value-weighted return on corporate bonds of rating class $j$ in excess of the 30-day T-bill return $j \in\{\mathrm{AAA}, \ldots, \mathrm{CCC} \&$ below $\}$. This specification is similar to that of Fama and French (1993), augmented with the two liquidity risk factors.

\section{ENTER TABLE 2}

Table 2 Panel A presents the coefficient estimates. For all ratings, the loadings on TERM and DEF are positive. The TERM factor loading is statistically significant for all rating classes and it is higher for the IG group of bonds (BBB and higher) than it is for junk bonds because the duration of IG bonds is generally higher. The DEF loadings are monotonically increasing down the rating groups (except for the CCC group), consistent with worsening of credit quality.

Of primary interest to this paper, the liquidity risk loadings $\beta_{S i}$ and $\beta_{B i}$ for both stocks and bonds, Silliq and Billiq, are negative for all ratings below BBB and are positive for highly rated bond classes (the coefficient of Silliq is positive for all investment-grade bonds and the coefficient of Billiq is positive for bonds above A-rating). Notably, the model includes the factor DEF, the bond market excess return over government bond return, which itself is negatively affected by illiquidity shocks (shown in Table 7 below). Then, the coefficients $\beta_{S i}$ and $\beta_{B i}$ measure the effects of liquidity shocks on returns in each rating

class (conditional on the effects of these shocks on DEF, the bond market excess return). The positive coefficients $\beta_{S i}$ and $\beta_{B i}$ then mean that the effects of illiquidity shocks on returns of highly rated bonds is less negative than their effect on the average bond market return and 
the negative coefficients $\beta_{S i}$ and $\beta_{B i}$ on junk bonds mean that these bond prices fall by more than average in response to illiquidity shocks. Overall, the coefficients on liquidity risks are almost monotonically declining from positive to negative values as we move from AAA down to CCC bonds. This pattern suggests a "flight to liquidity" phenomenon: When illiquidity rises, there is a flight from low-rated bonds which are generally less liquid to the more liquid higher-quality bonds. Consequently, the prices of high-rated corporate bonds rise and the prices of low-rated bonds fall, both effects being measured relative to the average bond market return. The explanatory power of our model is reasonably high for bonds rated BBB and above (adj- $R^{2}$ is between $75 \%$ and $82 \%$ ), but it deteriorates substantially for below-BBB bonds (adj- $R^{2}$ falls from $51 \%$ for BBB to $11 \%$ for CCC and below). ${ }^{9}$

Table 2 Panel B reports the economic magnitudes of the different factor loadings. In particular, it reports for each factor loading and each rating class how many standard deviation in returns arise from a standard deviation shock to the factor. The calculations employ the summary statistics reported in Table 1 and the coefficients estimated in Panel A of Table 2. For BBB and above, the liquidity risks are not economically significant: a one standard deviation shock to liquidity risks produces a meagre $0.6 \%$ to $9 \%$ of standard deviation in returns for these rating classes. The effects of TERM and DEF appear much more significant than those of liquidity risks for BBB and above, with the effect of TERM being the largest. But for junk bonds (BB and below), liquidity risk has greater economic significance for bond returns than its significance for IG bond returns (between 10\% to 40\%), while the effect of TERM declines. Notably, the effect of DEF does not rise substantially for bonds with rating lower than BBB.

In summary, Table 2 shows the existence of unconditional liquidity risk in corporate bond

\footnotetext{
${ }^{9}$ de Jong and Driessen (2007) estimate a bond return model with similar liquidity factors, using the stock market excess return instead of our two bond-market-based control variables, TERM and DEF, which render the market factor insignificant; see Gebhardt et al. (2005). Unlike in our results, their estimated coefficients of the illiquidity factors do not switch from positive for high-rated bonds to negative for lower-rated bonds which suggests flight to liquidity, and their liquidity factor coefficients are not as monotonic in the rating classes as we show them to be. This may be because their model does not include the bond market excess return factor DEF which itself has negative $\beta_{S i}$ and $\beta_{B i}$, as we show in Table 10, Panel A, column 1.
} 
returns, which is substantially higher for junk bonds than it is for investment-grade bonds. The switching signs of the liquidity risk as we move from high-rated to low-rated bonds suggests the phenomenon of flight to liquidity which we analyze in detail below.

\section{Conditional liquidity risk of bond returns}

Most of the current academic literature has focused on unconditional liquidity risk as we have also analyzed thus far. However, recent theoretical literature suggests that market liquidity and its impact on asset prices should be conditional as they fluctuate due to funding conditions. Brunnermeier and Pedersen (2009) show that funding illiquidity in the market adversely affects market liquidity when negative wealth shocks make margin constraints binding for financial intermediaries and force liquidations, or if margin constraints rise in times of higher volatility. Acharya and Viswanathan (2011) propose an endogenous link between wealth shocks and adverse market illiquidity. In their model, negative value shocks raise the leverage of financial intermediaries, which in turn can induce their managers to risk-shift ("gamble for resurrection") in order to gain at the expense of debt holders. As these firms need to roll over their short-term debt which continuously matures, they become capital-constrained because lenders are less willing to provide capital, knowing the risk-shifting propensity of the managers. Then, highly leveraged intermediaries are forced to liquidate their risky positions and asset markets can clear only at "cash-in-the-market" prices (see Shleifer and Vishny, 1992, Allen and Gale, 1994, 1998). He and Krishnamurthy (2012a,b) consider households which invest through intermediaries. Then, a negative wealth shock makes households rebalance their portfolios and allocate money away from risky to riskless assets, thus lowering intermediary wealth, causing capital constraints on intermediaries, and forcing asset sales and systemic liquidity problems.

This recent literature suggests that a given market liquidity shock generates greater effects on asset prices following negative wealth shocks to the economy (which are generally coincident with a rise in aggregate volatility) and especially shocks to financial intermediary 
capital. In normal times, liquidity shocks can be absorbed by financial intermediaries as they are far from their funding constraints and thus have ready capital for this purpose. But in times of adverse economic conditions and financial sector stress, financial intermediaries become more capital-constrained. Then, a given-size liquidity shock generates a greater effect on asset prices because liquidity providers are constrained all at the same time and require a higher liquidity premium, which in turn means greater asset price discount for a given liquidity shock. Further, in a bid to improve the liquidity of their balance sheets in such times, financial intermediaries exhibit greater aversion to holding less liquid assets and opt for more liquid ones.

This generates a link between adverse economic shocks and financial sector stress on the one hand and the return-liquidity risk relation on the other. Of particular relevance to corporate bonds is the fact that financial institutions are usually the marginal price-setters in these markets, so that this link should be more pronounced. ${ }^{10}$ We therefore test the following conditional effect of liquidity risk on corporate bonds: In episodes of adverse economic conditions, a rise in market illiquidity leads to a decline in all bond prices; however, in such periods investors substitute from less liquid to more liquid bonds, so that the effect of liquidity risk is exacerbated for less liquid (junk) bonds, while liquid (investment-grade) bonds become more desirable. ${ }^{11}$

\subsection{Regime-switching model of bond betas}

We perform a regime-switching analysis of corporate bond betas on various risk factors, separately for investment-grade and junk bonds. In essence, we let the data tell us whether there is a set of times when betas are substantially different than in other times. This method is used by Hamilton (1989) to study the apparent tendency of gross domestic product (GDP)

\footnotetext{
${ }^{10}$ This intuition is consistent with Garleanu and Pedersen (2009) who show that an asset's required return depends not only on traditional risk factors, but also on the asset's exposure to conditions that cause some of its marginal investors to face rising funding constraints, and on the share of such constrained investors among the asset holders.

${ }^{11}$ Amihud (2002, p. 45) provides a similar analysis for stocks.
} 
growth to behave quite differently during economic downturns. This differential behavior is a prevalent feature of financial data as well and the regime-switching approach has been used to examine how they could be detected in asset prices, as in Ang and Bekaert (2002a). Watanabe and Watanabe (2008) suggest a regime-switching pattern of the cross-sectional pricing of liquidity risk of stock returns, with the regime-switching being based on market

turnover. Ang and Timmermann (2011) estimate regime-switching models for stocks (the S\&P 500 excess returns), the three-month T-bill yields, and the foreign exchange excess return, suggesting that financial markets often change their behavior abruptly with the new behavior of financial variables persisting for several periods after such a change.

\subsubsection{Methodology}

We estimate a Markov regime-switching model for corporate bond betas, allowing the intercepts and the slope coefficients (betas) of bond return models to vary between two regimes. The model also allows the variance-covariance matrix to change between the two regimes. We use two value-weighted portfolio return series, one of investment-grade (IG) bonds and one of junk bonds.

Investment-grade bond excess returns (over the 30-day T-bill return) in Regime $k\left(s_{t}=k\right)$ for $k \in\{1,2\}$, are assumed to be generated by the process:

$$
\begin{aligned}
R_{I G, t} & =\alpha_{I G}^{k}+\beta_{I G, T}^{k} \times \text { Term }_{t}+\beta_{I G, D}^{k} \times \text { Def } f_{t} \\
& +\beta_{I G, S i}^{k} \times \text { Silliq }_{t}+\beta_{I G, B i}^{k} \times \text { Billiq }_{t}+\epsilon_{I G, t}^{k} .
\end{aligned}
$$

The state variable $s_{t}$ determines whether it is regime 1 or regime 2 and the Markov switching probability for state transition is specified as:

$$
\begin{aligned}
& P\left(s_{t}=1 \mid s_{t-1}=1\right)=p, \text { and } \\
& P\left(s_{t}=2 \mid s_{t-1}=2\right)=q .
\end{aligned}
$$


Similarly, junk grade bond excess returns (over the 30-day T-bill return) in Regime $k$ $\left(s_{t}=k\right)$ for $k \in\{1,2\}$, are assumed to be generated by the process:

$$
\begin{aligned}
R_{\text {Junk }, t} & =\alpha_{\text {Junk }}^{k}+\beta_{\text {Junk }, T}^{k} \times \text { Term }_{t}+\beta_{\text {Junk }, D}^{k} \times D e f_{t} \\
& +\beta_{\text {Junk }, S i}^{k} \times \text { Silliq }_{t}+\beta_{\text {Junk }, B i}^{k} \times \text { Billiq }_{t}+\epsilon_{J u n k, t}^{k} .
\end{aligned}
$$

The Regime Dependent Variance-Covariance Matrix is specified as $\left(s_{t}=1,2\right)$ :

$$
\Omega_{s_{t}}=\left(\begin{array}{cc}
\sigma_{I G, s_{t}}^{2} & \rho_{s_{t}} \sigma_{I G, s_{t}} \sigma_{J u n k, s_{t}} \\
\rho_{s_{t}} \sigma_{I G, s_{t}} \sigma_{J u n k, s_{t}} & \sigma_{J u n k, s_{t}}^{2}
\end{array}\right) .
$$

This flexible covariance structure is intended to capture the notion that variance of both the IG and junk returns as well as the correlation between the two can be different across the two regimes. The model is estimated using maximum likelihood estimation. Since the estimation procedure is standard (Hamilton, 1994), we do not provide details here but only the results. We test for linear hypothesis about the coefficients $H_{0}: L \beta=c$ where $L$ is a matrix of coefficients for the hypotheses and $c$ is a vector of constants. The Wald chi-squared statistic for testing $H_{0}$ is computed as $\chi_{W}^{2}=(L \hat{\beta}-c)^{\prime}\left[L \hat{V}(\hat{\beta}) L^{\prime}\right]^{-1}(L \hat{\beta}-c)$. Under $H_{0}, \chi_{W}^{2}$ has an asymptotic chi-squared distribution with $r$ degrees of freedom where $r$ is the rank of $L$ and $V$ is the variance-covariance matrix of the coefficients. Two points are in order before we proceed. One, the probabilities of state transition are assumed to be constant rather than varying with some exogenous condition. In this sense, the conditionality of this model arises purely from the regime switch rather than from the likelihood of the regime switch being based on some economic variable. We will however relate the estimated probability of being in regimes to macroeconomic and financial market variables. Second, the model also allows for residuals to be heteroskedastic across the two regimes. 


\subsubsection{Results}

The results in Table 3 Panel A show a clear pattern of two regimes in IG and junk bonds with the factor betas varying, especially for the two liquidity variables. In regime 1, the liquidity betas are mostly insignificant. For IG bonds, both liquidity betas are statistically insignificant and for junk bonds, the beta of Silliq is significant while that of Billiq is not. The liquidity betas in regime 2 present quite a different picture than they do in regime 1. For junk bonds, the betas of Silliq and Billiq become more negative with high statistical significance. The beta of Silliq rises threefold and that of Billiq rises fivefold compared to their magnitude in regime 1 . In contrast, for IG bonds, both liquidity betas become positive with high statistical significance. The coefficient of Silliq rises more than fourfold and that of Billiq turns from practically zero to positive. This means that the effect of illiquidity shocks on IG bond returns is significantly less negative than the effect of these shocks on the bond market excess return DEF.

\section{ENTER TABLE 3}

Panels B and C of Table 3 show statistical tests of significance for the differences in the liquidity betas. Importantly, the joint effect of the two liquidity variables is significantly different between the two regimes for both IG and junk bonds (Panel B), and it is also significantly different between IG and junk bonds in either regime 1 or regime 2 (Panel C). The difference between IG and junk bonds is less significant in regime 1 than it is in regime 2 .

The factors TERM and DEF too have some of their coefficients changing between regimes. Notably, while the beta of DEF rises in regime 2 for IG bonds, it remains practically unchanged for junk bonds. Comparing IG and junk bonds in regime 2 (Panel C), we note that while there is a significant difference between the effect of DEF on their values in regime 1, this difference disappears in regime 2. Then, both IG and junk bonds are similarly affected by DEF, in spite of their different likelihoods of default. The same applies to the betas of 
TERM: in regime 1, they are significantly different between IG and junk bonds while in regime 2 there is no significant difference between them. We examine whether there are lagged effects of the four explanatory variables by adding their two lagged values to the regime-switching model. We find that the lagged variables are not statistically significant.

A noteworthy difference between the two regimes is captured by the change in the sign of $\rho_{S t}$ which measures the correlation of residual returns between IG and junk bonds. While in regime 1 we obtain a small positive estimated value, estimate $\rho=0.10$, in regime 2 we obtain quite the opposite: $\rho=-0.40$. That is, in regime 2 , the returns which remain unexplained by our model go in opposite directions. ${ }^{12}$ This pattern is consistent with flight to quality and to liquidity in regime 2 by which investors switch from the riskier and less liquid junk bonds into IG bonds which are better in these two characteristics.

The picture that emerges from the results is as follows:

1. There is a sharp difference in regime 2 between the effects of liquidity shocks on prices of IG and junk bonds. The effects go in opposite directions, being positive for IG bonds and negative for junk bonds. This directional difference is absent in regime 1.

2. There is no significant difference in the effects of TERM and DEF between IG and junk bonds in regime 2, while in regime 1 there is a significant difference between them.

The model's alpha (the intercept), which measures the excess return after accounting for the TERM and DEF premiums, is higher for junk bonds than for IG bonds, being statistically significant only in regime 1. The higher alpha of junk bonds may reflect a premium for liquidity risk, which is higher for these bonds. The smaller premium (alpha differential between junk and IG bonds) in regime 2 may be caused by the negative realizations in junk bond returns in that regime, which is associated with economic stress (see below). ${ }^{13}$

\footnotetext{
${ }^{12}$ Pastor and Stambaugh (2003) show that in months when liquidity falls severely there is negative correlation between stock and fixed-income returns.

${ }^{13}$ Our model's results are robust if we control for default risk using each firm's equity returns value-weighted in the portfolio as in Shaefer and Strebulaev (2008) instead of DEF and change in equity market volatility as additional control variables.
} 
Next, we assess the contribution of the regime-switching model to the in-sample accuracy of estimation by regressing actual bond returns in each regime on predicted returns. Ideally, the intercept in this regression should be zero and the slope coefficient should obviously be 1.0. We generate predicted returns in two ways: (a) from the regime-switching model for that regime, and (b) from an unconditional model whose coefficients are the same for the entire sample period, obtained by estimating our model with fixed coefficients over 1973 2007.

Table 3 Panel D shows the estimated coefficients from the regression of actual returns on predicted returns. There are four regressions: for each of the two regimes, we do a regression for IG and junk bonds. Whereas the conditional model produces predicted returns that result in a slope coefficient of practically 1.0 (as trivially expected) and an intercept of zero, the predicted returns from the unconditional model result in a slope coefficient which is away from 1.0. In regime 1, the coefficients of the predicted returns are significantly below 1.0 for both IG and junk bonds, meaning an underestimation of positive returns and overestimates of negative returns. In regime 2 , it is the opposite. The predicted slope coefficient is greater than 1.0, implying that the predicted returns overestimate positive returns and underestimate negative returns. Altogether, the results from this table show the extent of improvement in the predictive power of the model when using our regime-switching regression.

As for the economic significance of the effect of liquidity risk on bond returns, we obtain that the effect roughly doubles in the stress regime. ${ }^{14}$ We measure the economic significance of the liquidity factors as Coeff $* \sigma_{\text {factor }} / \sigma_{\text {return }}$, where $\operatorname{Coeff}$ is the slope coefficient of the respective factor. Coeff and the two standard deviations are calculated separately for regimes 1 and 2. We observe that the economic significance of the effects of the two liquidity factors, Silliq and Billiq, is quite low in regime 1 but it greatly rises in regime 2. For IG bonds, the effect of Silliq rises from $2 \%$ to $8 \%$ and that of Billiq rises from $0.9 \%$ to $7 \%$. For junk bonds, the rise in the effect of Silliq is from $8 \%$ to $14 \%$ and for Billiq the rise is from

\footnotetext{
${ }^{14}$ Detailed results are available upon request.
} 
$4 \%$ to $13 \%$.

\subsubsection{The economic identification of regimes: Stress and macroeconomic factors}

So far we have derived the regimes from a purely statistical procedure without any economic input. The greater sensitivity of bond prices to default risk and liquidity risk in regime 2 suggests that regime 2 is associated with periods of economic stress. We now formally investigate this important issue. We undertake an economic identification of the regimes, using macroeconomic variables and confirm that regime 2 is indeed associated with economic conditions that can be collectively defined as "stress."

\section{ENTER FIGURE 4}

In Fig. 4, we plot the model-implied probability of being in the stress regime. ${ }^{15}$ The stress regime picks up most data points of being in a recession during the 1970s (picking up the oil-price shock of the mid-70s and the high interest-rate regime of the late 70s) and early 1980s (again, during the high interest-rate environment) and the financial market stress and the ensuing recession during the period 1998 - 2003. The regime-switching model also appears to pick up stress in 1989 leading up to the NBER recession of 1990 and 1991, and does not identify the mid-90s as a stress period. Yet, the Russian default and LTCM episode of 1998 are identified as being in the stress regime. The collapse of the Internet bubble in March 2000 and the economic downturn that followed (including the aftermath of the 9/11/2001 attack) are also identified as stress regimes. Finally, the probability of being in a stress regime rises starting in 2007 but not as dramatically (we later present out-of-sample analysis for 2008 - 2009).

We formally estimate the economic determinants of being in regime 2 by a multivariate regression model where the dependent variable is the probability of being in regime 2 , denoted

\footnotetext{
${ }^{15}$ This probability of being in state 2 is calculated at time $t$ as the sum of two products: the product of the transition probability from state 1 to state 2 with the probability of being in state 1 at time $t$-1, and the product of the transition probability from state 2 to state 2 with the probability of being in state 2 at time $t$-1. This sum is then multiplied by the ratio of the density under state 2 at time $t$ to the conditional density of the $t^{t h}$ observation. See Hamilton (1994) for details.
} 
P2. This probability is modeled as a function of economic and financial variables associated with market conditions and business cycles, observed with (at least) one-month lag. These variables are as follows (described in greater detail in Appendix A):

(i) NBER recession dummy variable: equals one in quarters defined by the NBER to be a recession. We exclude this variable from some of our estimations because the NBER declares a recession ex post with significant delay, while we want the information about the variables to be contemporaneous.

(ii) SW index: the Chicago Fed's CFNAI index a follow-up measure of the Stock and Watson $(1989,2002)$ recession index. Larger numbers indicate better business conditions.

(iii) Prob(Recession)-Hamilton: a dummy variable that equals one if the probability of recession estimated from a Hamilton (1989) model on US GNP growth rates is greater than 70\% (see Appendix B for its construction, also employing a regime-switching model).

(iv) Negative market return dummy variable: equals one if there have been three consecutive months of negative market returns (including the given month), based on the CRSP value-weighted market return.

(v) Business conditions index, due to Aruoba, Diebold, and Scotti (2009): it is designed to track real business conditions at high frequency. The average value of this index is zero. Bigger positive values indicate better-than-average conditions.

(vi) Paper-bill spread: the difference between the three-month nonfinancial commercial paper rate and the three-month T-bill secondary market rate. This spread indicates adverse financial and economic conditions.

(vii) TED spread: the difference between the interbank loan rate and the T-bill rate. This spread indicates adverse financial and economic conditions. Since the TED spread is highly correlated with the paper bill spread, we use the component that is orthogonal to the paper bill spread.

(viii) EE measure: the growth in balance-sheet of broker-dealers, as a measure of risk appetite of financial intermediaries motivated by Adrian and Shin (2010), and employed 
by Etula (2009). We use the growth in intermediaries' (aggregate broker-dealer) assets relative to household asset growth as a measure of aggregate speculators' ease of access to capital. This variable is constructed from the US Flow of Funds data which are available only at quarterly frequency for the full sample period. In our prediction, we use the growth rates based on the past one year's data. A rise in EE measure indicates expectations of good business conditions. However, when growth in this variable is coupled with equity market volatility, it indicates worsening conditions and involuntary increase in broker-dealer inventory.

(ix) Equity market volatility: the square root of the monthly average of the squared daily returns on the CRSP value-weighted index with dividends.

We do a pair of tests using two dependent variables. One is the probability of regime 2 for month $t, P 2_{t}$, which is estimated from our regime-switching model (see Hamilton, 1994). We employ a standard logit transformation of this probability, $\log \left[\left(P 2_{t}+c\right) /\left(1-P 2_{t}+c\right)\right]$, where $c=0.5 / 419$ is a constant that is added in order to accommodate the cases where we estimate $P 2=1$ or $P 2=0 .{ }^{16}$ The second is a dummy variable that equals 1.0 if $P 2_{t}>0.70$ (this threshold is also used by Hamilton, 1989). The first model is estimated by OLS and the second by logit.

\section{ENTER TABLE 4}

The estimation results, presented in Table 4, show that regime 2 is associated with economic downturns. The signs of all the macroeconomic and financial variables are consistent with the probability of regime 2 being higher in times of adverse economic conditions. We obtain positive coefficients for the NBER recession, Prob(Recession)-Hamilton, Negative market return dummy, Paper-bill spread, TED spread, and Equity volatility. These variables increase in value under economic stress. And, we obtain negative coefficients for SW index and for Business conditions index that rise in value in economic upturn, so their negative coefficients mean that the probability of regime 2 is associated with economic downturn. The

\footnotetext{
${ }^{16}$ See Cox (1970, p. 33).
} 
negative coefficient of the EE measure suggests that as broker-dealers foresee the good times and increase their inventories, or increase their risk appetite when the economy is headed into good times, regime 2 is less likely. But the interaction between Equity volatility and the EE measure is positive and significant. ${ }^{17}$ This means that in times of high volatility, a rise in the EE measure may indicate involuntary increase in intermediaries' inventories which is associated with a greater likelihood of the stress regime, which subsequently induces deleveraging events as observed in 2007 and 2008 in financial markets.

In general, the robust conclusion that emerges is that regime 2 is associated with adverse macroeconomic and stock market conditions. Hence, we call it the "stress" regime and regime 1 the "normal" regime. When employed in isolation, the explanatory power $\left(R^{2}\right)$ of the regime determinants is of the order of $11 \%$ to $28 \%$. When all variables are used to explain the model-implied probability of being in the stress regime, the $R^{2}$ exceeds $40 \%$. In the model with all variables (excluding the NBER recession dummy, which is known only ex post), those that emerge as having the greatest statistical significance are Prob(Recession)-Hamilton, Business conditions index, TED spread, EE measure, Equity volatility, and the interaction of the last two. In the logit regression with the stress regime dummy variable, the variable Negative market return dummy is also significant.

These results provide a measure of confidence that our regime-switching results on liquidity betas of bonds (Table 3) have sound economic foundations. In this light, it is clearer why in regime 2-the stress regime-there is greater sensitivity of bond returns to liquidity shocks and why bond returns become more sensitive to TERM and DEF, the term factor and the default risk factor. These two factors already reflect information about the business cycle. ${ }^{18}$ Notably, our result on shifts in regimes as business conditions change is obtained after controlling for the business cycle information captured by the changing values of TERM and DEF.

\footnotetext{
${ }^{17}$ See Comerton-Forde et al. (2010) on the interaction between dealers' inventories, liquidity, and volatility.

${ }^{18}$ For example, Fama and French (1989) identify the default spread as a business cycle variable, and Ang and Bekaert (2002b) find that short- and long-term government-bond interest rates exhibit regime-switching behavior which corresponds to business cycles (recessions) in the US
} 


\subsection{Out-of-sample regime prediction during 1990-2007}

The economic foundations of the stress regime (regime 2) enable us to predict its probability based on economic time-series and subsequently to predict corporate bond returns. We provide a prediction of the probability of being in regime 2 of the Markov regime-switching model of Table 3 using the economic variables identified in Table 4. First, we use a model similar to model (14) in Table 4 that includes all the economic indicators except the NBER recession (which is determined with hindsight) to predict the stress regime, employing only the data for the first half of our sample period, 1/1973 to 12/1989. After estimating the coefficients in this model, we predict the probability of being in the stress regime, $\hat{P} 2$, for the second half of the sample period, 1/1990 to $12 / 2007$, using a rolling estimation, month by month. That is, we roll forward every month, using the data available until the previous month to develop a predictive model for the stress regime and then use this model to predict stress regime for the current month, repeating this process until the end of the sample. For example, we predict the stress regime for the month 1/1990 using data until 12/1989 and coefficient estimates of a model similar to model (14) in Table 4. Then, for month 2/1990, we use all data until 1/1990 to re-estimate this model and generate $\hat{P} 2$, and so on.

After having obtained the series $\hat{P} 2$ for the period $1 / 1990-12 / 2007$, we do a logit regression of the likelihood of being in regime 2, obtained from our statistical model of Table 3, Panel A, on the predicted probability $\hat{P} 2$. The dependent variable is a dummy variable that equals one if the actual probability of being in regime 2, estimated from the regime-switching model, is above $70 \%$.

\section{ENTER TABLE 5}

The results in Table 5 show how well the likelihood of being in regime 2 is predicted by the economic series-based estimated regime- 2 probability $\hat{P} 2$. The coefficient of $\hat{P} 2$ is positive and significant, and its pseudo $R$-squared is $27 \%$. We demonstrate the performance of the model by its accuracy in discriminating regime-2 months from normal months, employing 
Receiver Operating Characteristic (ROC) curve analysis. The ROC curve analysis works as follows. For every possible cut-off point or criterion value selected in the logit model to discriminate between the two regimes, there is some fraction of cases with the stress months correctly classified as "True Positive" (TP) and some fraction of cases with the stress months classified "False Negative" (FN). Also, some fraction of normal months will be correctly classified as non-stress months or "True Negative" (TN) while some fraction of normal months will be classified as stress months or "False Positive" (FP). In an ROC curve, the TP rate (Sensitivity) is plotted as a function of the FP rate (1-Specificity) for different cut-off points of $\hat{P} 2$. Each point on the ROC plot represents a sensitivity/specificity pair corresponding to a particular decision threshold. A completely random guess would produce a point along a diagonal line (called line of no-discrimination) from the left-bottom to the top-right corners. A test with perfect discrimination (no overlap in the two regimes) has an ROC plot that passes through the upper-left corner (100\% specificity, 100\% sensitivity). Therefore, the closer the ROC plot is to the upper-left corner, the higher the overall accuracy of the test.

We present a figure that displays the ROC curve to assess the accuracy of this logit model to predict regime 2, the stress regime. In the $Y$-axis we plot the true positive rate (sensitivity), i.e., the proportion of actual stress regime months correctly classified by the model. In the $X$-axis we plot the false positive rate (1-specificity), the proportion of normal regime months, incorrectly classified as stress regime months by the model. Points above the diagonal (random guess) indicate good classification results. The area under the curve measures the accuracy of the model. The model has an accuracy rate which is quite high, $88.81 \%$. That is, using lagged economic conditions in real time, the model is able to predict the stress regimes in corporate bond returns with high accuracy. 


\subsection{Out-of-sample predictions of bond returns during 2008-2009}

We now test the accuracy of out-of-sample prediction of bond returns based on our regime-switching model during the financial crisis of 2008 and the relatively less stressed period of 2009. We predict the probability of a given month during 2008 and 2009 being in the stress regime by using the macroeconomic and financial market variables included in model (14) in Table 4 and the coefficients of that estimation model to obtain the predicted probability of being in regime 2. Then, we calculate the predicted bond returns for each regime in each month of 2008 and 2009 using the coefficients estimated on TERM, DEF, and liquidity risk factors in each regime shown in Table 3 Panel A and employing the realized values of TERM, DEF, and liquidity risk factors. Finally, we calculate the average return in the month by weighting the regime 1- and regime 2-predicted returns by the respective regime probabilities obtained in the previous step. This weighted-average return constitutes the predicted bond return for that month, conditional on the realized values of the four factors. For realized bond returns in each month of 2008 and 2009 for IG and junk bonds, we use data on iShares investment-grade and high-yield bond index, which are the most recent data available to us. ${ }^{19}$

\section{ENTER TABLE 6, and ENTER FIGURE 5}

In Table 6 Panel $\mathrm{A}$ we present the estimated values of $\hat{P} 2$, the regime- 2 probability. Notably, the period with the cluster of values equal or close to 1.0 is the second half of 2008 , especially following the Lehman Brothers collapse in September 2008. Later in 2009, $\hat{P} 2$ is mostly lower.

Table 6, Panel B presents results on the test of the quality of the predicted returns. We do that in a regression model of the actual bond return as function of the predicted bond return. In such a regression with an ideal predictor, the intercept should be zero and the slope coefficient should be 1.0. Our results satisfy these criteria. The slope coefficients on the

\footnotetext{
${ }^{19}$ The Merrill Lynch data on corporate bonds available to us end in December 2007.
} 
predicted returns are statistically indistinguishable from 1.0 (at the 0.10 level) for both IG and junk bond grades, and the constant is not different from zero in both these regressions. The regression has a reasonably good fit of $77 \%$ for the IG bonds and $76 \%$ for the junk grade bonds. Fig. 5 plots the actual-predicted return relation against the $45 \%$ line of perfect fit and shows that the two are quite close. In addition, the root mean squared error (RMSE) of the regression is very close to the RMSE of the $100 \%$ fit, again suggesting that the predicted returns do a good job in explaining the actual returns.

Overall, we conclude that our regime-switching model provides a good description of bond returns during the financial crisis year of 2008 as well as the relatively less stressed period of 2009. The model captures the dynamics of corporate bond returns both in regime 2, which in 2008 corresponds to all months except January and June, as well as in regime 1, corresponding to six months in the year 2009.

\section{Conditional liquidity risk of stock returns}

We extend our examination of conditional liquidity risk to stock returns of firms classified by their book-to-market ratio. Fama and French (1995, p. 154) state: "Firms with high $\mathrm{BE} / \mathrm{ME}$ (a low stock price relative to book value) tend to be persistently distressed. They have low ratios of earnings to book equity for at least 11 years around portfolio formation. Conversely, low BE/ME (a high stock price relative to book value) is associated with sustained strong profitability." This follows from their finding that firms with high book-to-market ratio tend to have low earnings on book equity which persist for at least five years before and five years after book-to-market equity is measured. High book-to-market stocks are also associated with lower liquidity. Fang, Noe, and Tice (2009) find in a cross-firms study that stocks which have higher illiquidity (measured by the effective bid-ask spread or by the Amihud illiquidity measure) have significantly lower market-to-book ratio (or, conversely, have higher book-to-market ratio) after controlling for firms' characteristics. It follows that high book-to-market stocks share the same characteristics as junk bonds: They are 
associated with greater economic distress and greater illiquidity. We test whether the impact of liquidity shocks on returns of stocks classified by their book-to-market ratio varies over time in the same way that it does for bonds, and whether these variations are also related to macroeconomic and financial conditions of stress, as we find that it is for bonds.

\subsection{Methodology}

We construct two portfolios of stock returns differentiated by book-to-market ratio and apply our regime-switching methodology to estimating the factors that affect their return. In every month (between 1973 - 2007), we use the classification of Fama and French of non-financial firm stocks in the CRSP database (NYSE, Amex, and Nasdaq) into the lowest and the highest book-to-market (BM) quintile portfolios and their returns in excess of the risk-free rate as our dependent variables in our regime-switching model.

We then estimate the following model that includes two sets of equations (Eq. 7 and Eq. 10), one for excess returns on low BM stocks and one for excess returns on high default-risk stocks. The model allows the coefficients as well as the variance-covariance matrix to change between the regimes. BM stock portfolio excess returns (over the 30-day T-bill return) in Regime $k\left(s_{t}=k\right)$ for $k \in\{1,2\}$, are assumed to be generated by the process:

$$
\begin{aligned}
r_{\text {Low }, t} & =\alpha_{\text {Low }}^{k}+\beta_{\text {Low }, \text { Rmt }}^{k}\left(R_{m, t}-R_{f, t}\right)+\beta_{\text {Low }, T}^{k} \text { TERM } \\
& +\beta_{\text {Low }, \text { Sit }}^{k} \text { Silliq }_{t}+\beta_{\text {Low }, D}^{k} D E F_{t} \\
& \text { Billiq }_{t}+\epsilon_{\text {Low }, t}^{k} .
\end{aligned}
$$

The state variable $s_{t}$ determines whether it is regime 1 or regime 2 and the Markov switching probability for state transition is specified as:

$$
\begin{aligned}
& P\left(s_{t}=1 \mid s_{t-1}=1\right)=p, \text { and } \\
& P\left(s_{t}=2 \mid s_{t-1}=2\right)=q .
\end{aligned}
$$


Similarly, high book-to-market stock portfolio excess returns (over the risk-free rate) in Regime $k\left(s_{t}=k\right)$ for $k \in\{1,2\}$, are assumed to be generated by the process:

$$
\begin{aligned}
r_{\text {High }, t} & =\alpha_{\text {High }}^{k}+\beta_{\text {High }, R m t}^{k}\left(R_{m, t}-R_{f, t}\right)+\beta_{H i g h, T}^{k} \text { TERM } \\
& +\beta_{\text {High }, D}^{k} D E F_{t} \\
& \beta_{\text {Low }, \text { Sit }}^{k} \text { Silliq }_{t}+\beta_{\text {Low }, \text { Bit }}^{k} \text { Billiq }_{t}+\epsilon_{\text {Low }, t}^{k} .
\end{aligned}
$$

The Regime Dependent Variance-Covariance Matrix is specified as $\left(s_{t}=1,2\right)$ :

$$
\Omega_{s_{t}}=\left(\begin{array}{cc}
\sigma_{\text {Low }, s_{t}}^{2} & \rho_{s_{t}} \sigma_{\text {Low }, s_{t}} \sigma_{\text {High }, s_{t}} \\
\rho_{s_{t}} \sigma_{\text {Low }, s_{t}} \sigma_{\text {High }, s_{t}} & \sigma_{\text {High }, s_{t}}^{2}
\end{array}\right) .
$$

The explanatory variables include the market excess return $R_{m}-R_{f}$, the value-weighted return on all NYSE, Amex, and Nasdaq stocks (from CRSP) in excess of the one-month Treasury bill rate (from Ibbotson Associates). We also include the variables TERM, DEF, Silliq, and Billiq that have been included in the bond return models. TERM and DEF are documented to have significant effects on stock returns (see Chen, Roll, and Ross, 1986; and Fama and French, 1989). Fama and French (1989, p. 48) state: "[t]he default spread is a business-conditions variable" and "the term spread is related to shorter-term measured business cycles." Indeed, the default yield spread (between AAA and BAA corporate bonds) is used by Bernanke (1983) as a proxy for financial and economic crisis, and the term yield spread is shown by Estrella and Mishkin (1998) and Estrella and Hardouvelis (1991) to predict real economic activity (particularly recessions). Stock and Watson (2002) review the extensive literature on the use of the default yield spread and of the term yield spread as predictors of output growth. In the context of our model, which estimates the effects of illiquidity shocks on stock expected returns, DEF and TERM serve to control for future business conditions which affect firms' expected cash flows. 


\subsection{Results}

The estimation results of the regime-switching model of stock returns are presented in Table 7, which is analogous to Table 3 in its structure. Here, returns on stocks with low and high book-to-market (BM) ratio replace the returns on bonds that are of investment grade and junk rating, respectively. We first focus on the coefficients of Silliq and Billiq which measure the effects of shocks in stock and bond illiquidity. In general, these effects have the opposite signs for the two stock portfolios. The coefficients of Silliq and Billiq are positive for low BM stocks and negative for high BM stocks (all conditional on the market). In regime 2, the effects of Silliq are significant and the difference between the coefficients for high and low BM stocks is significant as well (see the test in Panel C). The result here on the opposite relative effects of Silliq on stocks with high and low BM is similar to the result on the opposite relative effect of Silliq on junk and IG bonds, respectively, reported in Table 3. The coefficient of Silliq changes significantly between regimes only for the high BM stocks (see Panel B). In regime 2, the effect of Silliq on high BM stock returns becomes about five times more negative than it is in regime 1 . As noted earlier, in regime 2 , the effect of Silliq differs significantly between the low and high BM stocks at the $1 \%$ level whereas in regime 1, there is no significant difference in the effect of Silliq between the low and high BM stocks (see Panel C).

\section{ENTER TABLE 7}

Notably, the documented effects of Silliq are conditional on the positive effect of $R_{m}-R_{f}$, which itself is negatively affected by both Silliq and Billiq. Thus, the results mean that the effect of Silliq on returns of stocks with low BM is less negative than it is for the market, and the effect on high BM stocks is more negative than it is for the market. Estimating a model with only the two liquidity variables, Silliq and Billiq, we obtain that both variables have negative coefficients for both stock portfolios in both regimes. It is indeed expected that the beta of illiquidity shocks is negative because expecting higher illiquidity in the future 
following a rise in illiquidity, stock prices fall (see Amihud, 2002; and Acharya and Pedersen, 2005).

In this model, the coefficients of Silliq in regime 1 for low BM and high BM stocks are -267 and -273 , respectively, and in regime 2 they are -484 and -933 . All coefficients are significantly different from zero. These results mean that while in regime 1 the coefficients of Silliq are almost the same for both stock portfolios, in regime 2 the liquidity beta of high BM stocks is twice larger (more negative) than it is for low BM stocks. Also, the impact of illiquidity shocks is much higher in regime 2 than in regime 1 , particularly for high $\mathrm{BM}$ stocks. It follows that in normal times, illiquidity shocks have low and similar effects on both stock portfolios whereas in times of adverse economic conditions, there is "flight to liquidity" which makes low BM stocks relatively more desirable. This offsets part of the negative effect of Silliq for low BM stocks and augments its negative effect for high BM stocks.

The variable DEF does not have its effect changing between the two regimes for either portfolio but its effect is significantly different between the low and high BM stocks in both regime 1 and regime 2 (at the $1 \%$ and 10\% levels, respectively). The effect of TERM also does not change significantly between the two regimes. The market excess return has a highly significant effect on the returns of both stock portfolios, but this effect does not change between the regimes.

To summarize, the significant rise in the effect of Silliq in regime 2 for high BM stocks and the difference in its effect between the two stock portfolios in regime 2 , highlight the importance of liquidity risk, given that we control for the effects of business conditions and the likelihood of default. The effect of Billiq does not change significantly between the regimes but it is significantly different between the two portfolios in regime 1.

It is well known that the return on stocks with high book-to-market ratio is higher than the return on stocks with low book-to-market ratio - this is the well-know HML premium. In our regime-switching model, we compare the conditional means of the two stock portfolios, measured by the models' intercepts (alphas), which measure the return in excess of the 
premium due to $R_{m}-R_{f}$, TERM, and DEF. Here, we observe that the difference between the intercepts is significant only in regime 1 but not in regime 2. Given our result on higher liquidity betas for high BM stocks, the higher conditional mean on HML may reflect compensation for the greater liquidity risk of high BM stocks. In regime 2, which is associated with adverse economic conditions, the difference in the conditional means becomes insignificant because of greater realized losses on the high BM stocks which Fama and French (1995) classify as distressed stocks.

It is therefore possible to regard the well-known HML premium as compensation (at least in part) for higher liquidity risk, earned mainly in the "normal" regime, regime 1. This premium disappears in regime 2. We observe in Panel $\mathrm{C}$ that the constant of the model - the excess return after accounting for the risk premia - is significantly higher for high BM stocks in regime 1, whereas in regime 2 the difference in the constants is quite insignificant.

\subsection{The economic identification of regimes: Stress and macroeconomic factors}

Next, in Table 8 we estimate the economic determinants of being in regime 2 in the case of stocks by a multivariate regression model, similar to that presented in Table 4 for the case of corporate bonds. The dependent variable is the probability of being in regime 2, denoted P2. This probability is plotted in Fig. 6, with the NBER recession indicator which shows a good overlap between these variables. Thus, this probability is modeled as a function of economic and financial variables associated with market conditions and business cycles with one-month lag, the same as those that we have used for the corporate bond-based regime-switching model. We do two estimations, one is an OLS estimation of a standard logistic transformation ${ }^{20}$ of $P 2$, and the other is a logit estimation of a dummy variable that equals 1.0 if $P 2_{t}>0.70$ a threshold used by Hamilton (1989).

\section{ENTER TABLE 8}

\footnotetext{
4 .

${ }^{20}$ We again employ $\log \left[\left(P 2_{t}+c\right) /\left(1-P 22_{t}+c\right)\right]$, where $c=0.5 / 419$ is a constant. See discussion of Table
} 
The estimation results show again that regime 2 is associated with times of adverse economic conditions. This is consistent across all variables. We obtain positive coefficients for Prob(Recession)-Hamilton, Negative market return dummy, and Equity volatility. These variables rise in value under economic stress. And, we obtain negative coefficients for SW index and for Business conditions index, which rise in value in economic upturns. The negative coefficient on the EE measure suggests that as broker-dealers foresee good times and increase their inventories or increase their risk appetite, regime 2 is less likely. But during volatile times, greater broker inventory growth is associated with a greater likelihood of subsequent stress regime (the interaction between Equity volatility and the EE measure is positive and significant), similar to the deleveraging events observed in 2007 and 2008 in financial markets.

When all variables are used to explain the model-implied probability of being in the stress regime (excluding the NBER recession indicator, which is known only ex post), the $R^{2}$ is $30 \%$ in the OLS regression of the probability of regime 2, and $21 \%$ for the logit regression. The evidence thus shows that regime 2 , in which illiquidity shocks as well as default shocks become significantly more important in pricing stocks of high and low default risk, is associated with worsening macroeconomic and financial market conditions.

\subsection{Direct relation to default risk}

The model estimated in Table 7 uses conventional measures to control for cash-flow risk and default risk. We now provide direct control for default risk, calculated as the return premium on stocks sorted on their default probability. With this control we test whether the book-to-market return is explained by the default premium and whether, after controlling for default, we still observe conditional liquidity risk in times of adverse economic conditions. This will then highlight the fact that liquidity risk has a separate effect from default risk.

We construct two portfolios of stock returns differentiated by default risk. In every month (between 1973 - 2007), we classify non-financial firm stocks in the CRSP database 
(NYSE, Amex, and Nasdaq) into 25 (5x5) portfolios sorted on stock return volatility and on their modified $Z$-score (an estimate of the likelihood of default, not based on stock market values). This is done so as not to confound the effect of default with that of volatility, given the positive correlation between them across firms, documented by Campbell et al. (2008), and the negative effect of return volatility on expected return, shown by Amihud (2002) and Ang et al. (2006). ${ }^{21}$ For each month we calculate for each stock the modified $Z$-score, ${ }^{22}$ using the most recent accounting data and end-of-month market value data, and the standard deviation of daily stock returns from that month. Then we sort stocks into five equal volatility-based quintiles and within each quintile we sort the stocks into five equal portfolios based on the modified $Z$-score. We then calculate the value-weighted return for each of the 25 portfolios. The low (high) default-risk stock return is the average return of the five portfolios with the highest (lowest) modified $Z$-score, respectively. We use an accounting-based measure of default risk in order to avoid issues with stock return-based measures of default-risk, given that our dependent variable is itself a stock return. For example, because debt levels change very little in the short run, using a stock-market-based measure of default probability, which is based on equity market value and volatility, may capture the effects of past stock returns and volatility on current returns even if this is unrelated to default.

The excess return on high book-to-market stocks is known to be positive and significant (Fama and French, 1993), and so it is in our sample. We calculate the excess return HMLBM which stands for high-minus-low book-to-market, the differential return on the two extreme quintile stock portfolios Hi BM and Lo BM. The mean HMLBM is 50 basis points (per

\footnotetext{
${ }^{21}$ By classifying on both volatility and the likelihood of default, we follow the methodology of Fama and French (1993, pp. 8 - 9) who construct their HML index so as not to confound the book-to-market effect with the size effect.

${ }^{22}$ The modified Z-score, which relates to that of Altman, follows the specification of Hillegeist et al. (2004): $-4.34-0.08 *$ wcta $+0.04 *$ reta- $0.1 *$ ebitta- $0.22 *$ mvliab $+0.06 *$ sata. wcta is the ratio of working capital to total assets (Compustat item (actq-lctq)/atq). reta is the ratio of retained earnings to total assets (Compustat item req/atq). ebitta is the ratio of earnings before interest and taxes to total assets (Compustat item (piq+xintq)/atq). mvliab is the ratio of market value of equity to total liabilities (Compustat item prccq*cshoq/ltq). sata is the ratio of sales to total assets (Compustat item saleq/atq).
} 
month) with $t=2.96$. We also calculate HMLDEF, the differential return on the two extreme quintile stock portfolios sorted on their default probability. HMLDEF thus captures the return premium due to default risk, unrelated to liquidity risk. We examine the relation between HMLDEF and liquidity shocks by regressing it on Silliq and Billiq and find that the coefficients are insignificantly different from zero. The mean HMLDEF is 58 basis points with $(t=2.42)$, about the same as that HMLBM.

We then estimate a regime-switching model where HMLBM is regressed on HMLDEF, Silliq, Billiq, and a constant, allowing for the estimated parameters to vary between the regimes as we do in Eqs. (7) - (9) (we skip the detailed presentation to save space). The estimation results are presented in Table 9.

\section{ENTER TABLE 9}

The positive and highly significant coefficient of HMLDEF in both regimes suggests that the well-known HMLBM return premium is largely explained by the default premium. The models' intercepts, the alphas, become insignificantly different from zero in both regimes; in regime 1, the "normal" regime, the intercept is even negative though quite insignificant. The coefficient of HMLDEF rises in regime 2, but the difference between the coefficients is not statistically significant (see Panel B). The only significant difference between the estimated coefficients in the two regimes is observed for Silliq. Its coefficient is 9.38 in regime 1 with $t=0.05$, being practically zero, whereas in regime 2 the Silliq coefficient becomes highly negative, -433.39 , with $t=4.89$, highly significant. The difference between the coefficients of Silliq in the two regimes is statistically significant (see Panel B). The coefficient of Billiq also becomes more negative in regime 2 , but it is insignificantly different from zero in both regimes.

In conclusion, the difference between the two regimes is mainly driven by the significant increase in the stock liquidity risk: its coefficient becomes negative and highly significant in regime 2 , which is associated with adverse economic conditions, after accounting for default 
risk, which is captured by HMLDEF.

\subsection{Relation between stress regimes for bonds and stocks}

The estimations of the three regime-switching models in Tables 3, 7, and 9 produce monthly estimates of the probability of being in regime 2. We now relate these estimates of the probability of the "stress" regime-regime 2-to each other. Notably, they are estimated separately from corporate bond and stock returns in different models. For convenience, denote the variable Prob(Regime 2) $)_{t}^{\text {Bond }}$, estimated from the model for bond returns in

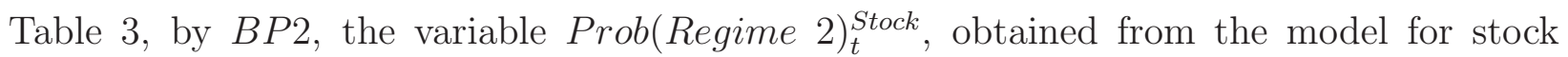

returns in Table 8 by $S P 2$, and the variable Prob(Regime 2$)_{t}^{\text {Default }}$, obtained from Table 9, by DefP2. If these three series indeed reflect similar economic conditions, they should be positively correlated. Indeed, Tables 4 and 9 show that $B P 2$ and $S P 2$ are predicted by the same economic variables. This can also be seen by visually inspecting $B P 2$ and $S P 2$ in Figs. 4 and 6, respectively. Confirming this, we find the following:

$$
\begin{aligned}
& \operatorname{Corr}\left(B P 2_{t}, S P 2_{t}\right)=0.57 \\
& \operatorname{Corr}\left(B P 2_{t}, \text { DefP2 } 2_{t}\right)=0.48 \\
& \operatorname{Corr}\left(S P 2_{t}, \operatorname{DefP} 2_{t}\right)=0.52
\end{aligned}
$$

These correlations are highly significant with $p$-values of less than 0.01 . However, all three series are highly serially correlated, so we use their first difference, denoted by $\Delta B P 2_{t}$, $\triangle S P 2_{t}$, and $\triangle D e f P 2_{t}$ whose serial autocorrelations are low. Regressing $\triangle B P 2_{t}$ on $\triangle S P 2_{t}$ (and a constant), the coefficient is 0.15 with $t=2.98$, statistically significant. Again, we observe that the two estimates of the probability of regime 2, obtained from separate sets of securities - stocks and bonds - are positively and significantly correlated. Finally, we regress $\triangle D e f P 2_{t}$ on the other two first differences in probability of regime 2 (and a constant). The coefficient of $\triangle S P 2_{t}$ is $0.10(t=4.73)$ and the coefficient of $\triangle B P 2_{t}$ is $0.08(t=3.51)$, both are highly significant. The strong link between the estimated probabilities of being in 
regime 2 for both bonds and stocks suggests that these probabilities are driven by common underlying factors.

\subsection{The co-movement of asset returns in the stress regime}

A popular hypothesis states that asset returns co-move more closely together in stress periods caused by liquidity shocks. We examine this hypothesis by creating two variables, $R_{\text {Junk }} r_{\text {High }}$ which is the product of return on junk bonds and returns of the high BM stock portfolio, both related to firms that are in financial distress (see Fama and French, 1995), and we create an analogous series, $R_{I G} r_{\text {Low }}$, the product of returns on investment-grade bonds and on low BM stocks, both associated with firms that are in better financial condition. A positive product implies that the two asset returns move more closely together in the same direction.

We estimate a regression model of $R_{I G} r_{\text {Low }}$ or $R_{J u n k} r_{H i g h}$ on BP2 (and a constant). A positive coefficient of $B P 2$ is then consistent with the above hypothesis. We obtain that indeed when the dependent variable is $R_{J u n k} r_{H i g h}$, the coefficient of $B P 2$ is positive and highly significant: it is 51,254 (in bp) with $t=3.53 .{ }^{23}$ The coefficient of $B P 2$ with $R_{I G} r_{\text {Low }}$ as the dependent variable is quite insignificant $(t=-0.44)$. When adding $R_{m}-R_{f}$ to the model with $R_{\text {Junk }} r_{\text {High }}$ as dependent variable, the coefficient of BP2 remains positive, 56,068, with $t$ $=3.96$, highly significant, and the coefficient of $R_{m}-R_{f}$ is positive and significant $(t=4.92)$. The coefficient of $B P 2$ with $R_{I G} r_{\text {Low }}$ as the dependent variable remains insignificant $(t=$ -0.03) when $R_{m}-R_{f}$ is added to the model. Similar results are obtained when replacing $B P 2$ by $\hat{B} P 2$ from Table 4, estimated by specification (14). These results support the hypothesis that returns on distressed assets co-move more closely together in times of economic stress whose likelihood is estimated by our regime-switching model.

\footnotetext{
${ }^{23}$ The $t$-statistics are calculated using robust standard errors.
} 


\section{Discussion}

\subsection{Flight to liquidity, default risk, and T-bill returns}

One interpretation of our results is that, consistent with the literature on asset pricing with frictions discussed in Section 4, stressed macroeconomic and financial conditions make investors more averse to illiquidity shocks and they respond by switching from illiquid assets, such as junk bonds, to investment-grade bonds which are known to be more liquid. ${ }^{24}$ An alternative explanation is that the rise in the effect of liquidity shocks on bond prices proxies for heightened investor risk-aversion to extreme events or rare disasters (Rietz, 1988; and Barro, 2006). Such events are argued to affect consumption significantly or are argued to be not well understood, so that an increase in their likelihood induces an aversion to riskier assets such as junk bonds. Similar to this second explanation is the volatility feedback explanation of Campbell and Hentschel (1992) by which increases in aggregate volatility necessitate a reduction in investor holdings of risky assets, which in general equilibrium, implies lower contemporaneous returns. In what follows, we test for distinct effects of risk and liquidity on bond prices which imply, respectively, flight-to-quality/safety or flight-to-liquidity (or both).

\section{ENTER TABLE 10}

Column 1 in Table 10, Panel A, shows that the factor DEF captures only the common part of the illiquidity effect on IG and junk bond returns, but not the part that is associated with regime 2. While both Billiq and Silliq effects are statistically significant, Adj $R^{2}$ is quite low, only $3 \%$, and the interaction of liquidity factors and Prob(Regime 2) Bonds is insignificant. The pattern that emerges is that default risk is distinct from liquidity risk, especially in the stress regime identified using corporate bond returns.

In columns 2 and 3, the dependent variable is -(T-bill yield minus Fed funds rate). This variable, which rises with the price of T-bills, is immune to default risk, reflecting only

\footnotetext{
${ }^{24}$ Chen, Lesmond, and Wei (2007) show that generally, investment-grade bonds have lower bid-ask spread, (quoted or implied) than junk bonds. Also, the frequency of zero-return days, another common proxy of illiquidity, is of the order of $6 \%-10 \%$ for investment-grade bonds and $20 \%-40 \%$ for junk bonds.
} 
liquidity risk. It is also immune to policy effects and to maturity risk because the Fed funds rate is for very short maturities. ${ }^{25}$ If a rise in illiquidity generates flight to liquidity, then investors will switch from all types of risk and illiquid investments to short-term T-bills which are the least risky and most liquid instrument. Then, their price will rise and their yield will fall and -(T-bill yield minus Fed funds rate) will rise. It is worth noting that the inclusion of Prob(Regime 2) $)^{\text {Bonds }}$ and its association with bond illiquidity greatly raises the explanatory power of the model, from $A d j R^{2}$ of $3 \%$ to $A d j R^{2}$ of $12 \%$, demonstrating the importance of our estimates of Prob(Regime 2) Bonds on the pricing of Treasury bills, which become a haven for liquidity seekers in times of stress. Also notable is the result that T-bills' prices rise with an increase in illiquidity only in regime 2-the coefficient of Billiq is practically zero while the coefficient of Prob(Regime 2) Bonds * Billiq is positive and significant. This shows that the behavior of Treasury bills' prices is similar to that of investment-grade bonds. In contrast, T-bill returns do not vary with an increase in default risk in the stress regime (Prob (Regime


rather than a flight-to-quality.

Comparing specifications (2) and (4), it is worth noting that the inclusion of Prob(Regime $2)^{\text {Stocks }}$ and its association with bond illiquidity greatly raises the explanatory power of the model: $A d j R^{2}$ rises from $3 \%$ to $6 \%$. This demonstrates the importance of our estimates of Prob(Regime 2) Stocks as well on the pricing of Treasury bills, and, while T-bill returns

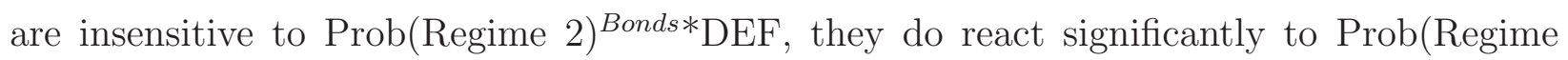
$2)^{\text {Stocks* DEF. }}$

\subsection{Flight to liquidity and bond maturity}

In Table 10, Panel B, we first study how the differential bond return-Junk return minus IG return - is explained by default and liquidity risks in normal times and in times of stress (regime 2) identified in the bond return regime-switching model. The estimation

\footnotetext{
${ }^{25}$ This is similar to the test of Amihud and Mendelson (1991) on the yield spread between T-bills and Treasury notes of the same maturity.
} 
in column 1 omits the liquidity variables, which are included in column 2. Two points are noteworthy. First, the inclusion of the liquidity variables greatly raises (by almost two-thirds) the explanatory power of the model, from $A d j R^{2}=11 \%$ to $A d j R^{2}=18 \%$. This attests to the importance of liquidity risk in determining the junk-IG differential return. Second, the effect of the two liquidity variables is significant mainly when associated with Prob(Regime 2 ), the probability of the stress regime. The negative and significant coefficients of the liquidity risk factors in stress times indicate flight to liquidity, in addition to the flight to safety which is captured by the negative coefficient of Prob(Regime 2)*DEF.

We expect that the effects of liquidity shocks on bond returns that we have documented are greater for longer-maturity bonds, which have greater duration in the sense of having greater price elasticity to yield change. Also, because long-term corporate bonds are less liquid than short-term bonds (see Chen et al., 2007), we expect that long-term bond returns are more sensitive to liquidity shocks than are short-term bond returns. To test this, we create three portfolios of junk-minus-IG returns for three different maturities: short-less than four years to maturity, medium — between four and nine years to maturity, and long — more than nine years to maturity. We expect that in the stress regime (regime 2), the effects of liquidity shocks will increase with maturity.

The results in the last three columns (3, 4, and 5) of Table 10 Panel B are consistent with our expectations. The coefficients of Silliq and Billiq are all negative, because a rise in illiquidity lowers the prices of the less-liquid junk bond relative to that of the more liquid IG bonds. Notably, the effects of both Silliq and Billiq become much more negative and highly significant when interacting with Prob(Regime 2), with the effect being stronger for longer-maturity bonds. This means that in the stress regime, the differential effect of illiquidity shocks on the junk-IG return spread is particularly high. These effects of liquidity risk are present after controlling for the effect of default risk (captured by the factor DEF), in both normal times and stress times. 


\section{Related literature on bond yields and liquidity}

The effect of liquidity on bond yields is shown for government securities that have the same risk but differ in their liquidity by Amihud and Mendelson (1991), Boudoukh and Whitelaw (1993), Kamara (1994), Elton and Green (1998), and Longstaff (2004). They all find that the bond yield rises as a function of illiquidity.

For corporate bonds, Chen, Lesmond, and Wei (2007) find that less liquid bonds (mostly speculative-grade bonds) have higher yield after controlling for default risk and other bond features. de Jong and Driessen (2007), Downing, Underwood, and Xing (2009), and Lin, Wang, and $\mathrm{Wu}$ (2011) find that expected return on corporate bonds is increasing in their liquidity risk (beta), following the analysis for stocks in Pastor and Stambaugh (2003) and Acharya and Pedersen (2005).

Recent studies, for example, Goldstein, Hotchkiss, and Sirri (2007), Edwards, Harris, and Piwowar (2007), Dick-Nielsen, Feldhutter, and Lando (2008), Bushman, Le, and Vasvari (2009), and Friewald, Jankowitsch, and Subrahmanyam (2009), use newly available daily trading data on corporate bonds from TRACE platform in the United States (starting in 2002). Some of these studies show that liquidity worsened substantially for corporate bonds from the onset of the crisis $(3 \mathrm{Q} / 2007)$ and that this contributed to an enhanced response of bond spreads or returns to liquidity. Chacko (2005) and Mahanti et al. (2008) measure

liquidity of corporate bonds by the turnover of portfolios that contain them, construct a bond return factor based on high and low liquidity bonds, and find that its beta coefficient explains the cross-section of bond returns.

Our study differs from the above studies on the effects of liquidity on corporate bonds in that we use liquidity measures that enable the study of long time-series, spanning several economic cycles, allowing more robust inference on expected returns. Goyenko (2006) also studies the cross-market effect of liquidity over a long time-series and finds that stock returns as well as Treasury bond returns are affected by both stock and bond liquidity shocks. In contrast, we study the effect of liquidity conditional on the state of the economy and find 
the conditional effects to be substantial, both for corporate bond returns and for returns on portfolios of stocks sorted by default risk.

Finally, recent work (Panyanukul, 2009) has also found liquidity risk to be a priced factor in explaining sovereign bond returns, especially during the period 2007 to 2009. We conjecture that there is a strong conditional component to liquidity effects in sovereign bond returns too, whereby during times of macroeconomic and financial market stress, better-rated and more liquid sovereign bonds (e.g., the US treasuries and German Bunds) appreciate in value whereas the worse-rated and less-liquid ones decline.

\section{Concluding remarks}

Our analysis of the effect of conditional liquidity risk on corporate bond returns shows that during economic and financial stress periods, liquidity risk becomes a significant determinant of bond prices, appreciably more so than in normal times. We find that investors exhibit "flight to liquidity" wherein liquidity shocks raise the prices of investment-grade bonds while depressing the prices of junk bonds (all, relative to the effect on the general bond market). This pattern is most strongly pronounced in times of economic stress. Thus, using unconditional or normal-time models entails significant errors for researchers and investors in corporate bonds. For instance, the risk management of corporate bond portfolios should consider not only their liquidity risk, but also the risk that this risk will change in stressed market and economic conditions.

We also find that the conditional liquidity risk patterns observed in corporate bond returns are mirrored in returns of stocks aggregated in portfolios of firms with high and low book-to-market ratio. Since high book-to-market ratio indicates persistent distressed profitability (Fama and French, 1995) as well as lower stock liquidity (Fang, Noe, and Tice, 2009), this suggests that the rise in liquidity risk of distressed securities is coincident between corporate bond and stock markets. We indeed find that the very same economic and financial factors that explain the regimes in the bond market do that for regimes in the stock market. 
We also show that the return premium on a high-minus-low book-to-market stock portfolio is largely explained by the default premium. However, when economic conditions change, the exposure to the default factor remains unchanged while the exposure to liquidity shocks increases under adverse economic conditions.

\section{Appendix A. Recession dates (year-month) based on macroeconomic data.}

NBER business cycles: The economic expansions and recessions are determined by the NBER business-cycle dates. The expansions (recessions) begin at the peak (trough) of the cycles and end at the trough (peak). The following provides periods and durations (in months) of each business-cycle phase during our sample period, January 1973 to December 2007. The business-cycle dates are available from the NBER Web site: www.nber.org/cycles.html. The dates are 12/73 - 03/75;02/80 - 07/80;08/81 - 11/82;08/90 - 03/91;03/01 - 11/01; and $12 / 07$.

Prob(Recession)-Hamilton: Following Hamilton (1989), we estimate the growth in GNP as a regime switching model (details in Appendix B). Hamilton (1989) interprets the probability of being in regime 1 as the recession regime. We use a cut off of the probability of being in regime 1 greater than $70 \%$ to create this dummy variable. Quarters that are classified as recession in this approach include: $1974-2$ to $1975-1 ; 1980-2,3 ; 1981-2 ; 1981-4$ to $1982-4$; 1986-2; 1990-3 to $1991-4 ; 1993-2,3 ; 1995-2,3 ; 1998-2 ; 2000-3$ to 2003-1; 2006-3 to 2007-1.

Mkt return (negative): We code a month that is the third consecutive month in which the CRSP value-weighted market return with dividends is negative as a one and zero otherwise. Months classified under this classification using our sample period include: 03/73 to 06/73; $05 / 74$ to $09 / 74 ; 09 / 75 ; 03 / 77 ; 08 / 81$ to $09 / 81 ; 02 / 82-03 / 82 ; 07 / 82 ; 02 / 84 ; 11 / 87 ; 08 / 90$ to $10 / 90 ; 09 / 99 ; 11 / 00 ; 08 / 01-09 / 01 ; 06 / 02-07 / 02 ; 12 / 02 ; 02 / 03 ; 07 / 06 ;$ and $09 / 07$ to $12 / 07$. 
SW index : "The Chicago Fed National Activity Index (CFNAI) is a monthly index designed to better gauge overall economic activity and inflationary pressure. The CFNAI is a weighted average of 85 existing monthly indicators of national economic activity. It is constructed to have an average value of zero and a standard deviation of one. Since economic activity tends toward trend growth rate over time, a positive index reading corresponds to growth above trend and a negative index reading corresponds to growth below trend. The CFNAI corresponds to the index of economic activity developed by James Stock of Harvard University and Mark Watson of Princeton University in an article, "Forecasting Inflation," published in the Journal of Monetary Economics in 1999. The idea behind their approach is that there is some factor common to all of the various inflation indicators, and it is this common factor, or index, that is useful for predicting inflation. Research has found that the CFNAI provides a useful gauge on current and future economic activity and inflation in the United States." (Reproduced from www.chicagofed.org.) An index similar in spirit is also the business conditions index which is also used in the analysis. The (ADS) business conditions index is based on the framework developed in Aruoba, Diebold, and Scotti (2009). The average value of the index is zero. Progressively bigger positive values indicate progressively better-than-average conditions, whereas progressively more negative values indicate progressively worse-than-average conditions.

\section{Appendix B. Estimation of recession periods using Hamilton's (1989) Markov switching model}

This appendix reports the results of the following Markov switching model for the quarterly growth rate in US GNP $\left(y_{t}\right)$ :

Regime $1\left(s_{t}=1\right): y_{t}=\alpha_{1}+u_{t}$, and

Regime $2\left(s_{t}=2\right): y_{t}=\alpha_{2}+u_{t}$, where 
$u_{t}=\rho_{1} u_{t-1}+\rho_{2} u_{t-2}+\rho_{3} u_{t-3}+\rho_{4} u_{t-4}+e_{t}, e_{t} \sim N(0, \sigma)$.

The Markov switching probability for state transition is given by:

$P\left(s_{t}=1 \mid s_{t-1}=1\right)=p$, and

$P\left(s_{t}=2 \mid s_{t-1}=2\right)=q$.

Following Stock and Watson's (2002) observation of a structural break in the GNP series in 1984, we estimate the model for two distinct time periods: 1952 (Quarter 2) to 1984 and from 1985 to 2008 (Quarter 3). We use these models to estimate the probability of being in regime 1 interpreted by Hamilton (1989) as the recession regime which is used in specifications of Table 4.

\begin{tabular}{lcccccc}
\hline Period & $1952: 2$ to $1984: 4$ & & & & \\
Parameter & Value & Std.error & $t$-Value & Value & Std.error & $t$-Value \\
\hline$\alpha_{1}$ & -0.3403 & 0.2441 & -1.39 & 0.8738 & 0.1880 & 4.65 \\
$\alpha_{2}$ & 1.1727 & 0.1423 & 8.24 & 1.5922 & 0.2223 & 7.16 \\
$\rho_{1}$ & 0.0108 & 0.0895 & 0.12 & -0.2506 & 0.0992 & -2.53 \\
$\rho_{2}$ & -0.0627 & 0.0811 & -0.77 & 0.1994 & 0.0822 & 2.43 \\
$\rho_{3}$ & -0.2462 & 0.0859 & -2.87 & -0.0532 & 0.0845 & -0.63 \\
$\rho_{4}$ & -0.2009 & 0.0867 & -2.32 & 0.0391 & 0.0802 & 0.49 \\
$\sigma$ & 0.7699 & 0.0608 & 12.66 & 0.3246 & 0.0321 & 10.12 \\
$p$ & 0.9014 & & & 0.7502 & & \\
$q$ & 0.7620 & & & 0.8578 & & \\
Log L & -181.4 & & & -56.44 & & \\
\hline Observations & 131 & & & 95 & \\
\hline
\end{tabular}




\section{References}

Acharya, V., and Pedersen, L., 2005. Asset pricing with liquidity risk. Journal of Financial Economics 77, 375-410.

Acharya, V., Viswanathan, S., 2011. Leverage, moral hazard and liquidity. Journal of Finance 66, 99-138.

Adrian, T., Shin, H., 2010. Liquidity and Leverage. Journal of Financial Intermediation $19,418-437$.

Allen, F., Gale, D., 1994. Liquidity preference, market participation and asset price volatility. American Economic Review 84, 933-955.

Allen, F., Gale, D., 1998. Optimal financial crises. Journal of Finance 53, 1245-1284.

Amihud, Y., 2002. Illiquidity and stock returns: Cross-section and time series effects. Journal of Financial Markets 5, 31-56.

Amihud, Y., and Mendelson, H., 1986. Asset pricing and the bid-ask spread. Journal of Financial Economics 17, 223-249.

Amihud, Y., and Mendelson, H., 1991. Liquidity, maturity, and the yields on U.S. treasury securities. Journal of Finance 46, 1411-1425.

Ang, A., and Bekaert, G., 2002a. International asset allocation with regime shifts. Review of Financial Studies 15, 1137-1187.

Ang, A., and Bekaert, G., 2002b. Regime switches in interest rates. Journal of Business and Economics Statistics 20, 163-182.

Ang, A., Hodrick, R., Xing, Y., Zhang, X., 2006. The cross-section of volatility and expected returns. Journal of Finance 61, 259-299. 
Ang, A., and Timmerman, A., 2011. Regime changes and financial markets. Unpublished working paper, Columbia University and University of California at San Diego.

Aruoba, S., Diebold, F., Scotti, C., 2009. Real-time measurement of business conditions. Journal of Business and Economic Statistics 27, 417-427.

Barro, R., 2006. Rare disasters and asset markets in the twentieth century. Quarterly Journal of Economics 121, 823-866.

Bernanke, B., 1983. Nonmonetary effects of the financial crisis in propagation of the great depression. American Economic Review 73, 257-276.

Bharath, S., and Shumway, T., 2008. Forecasting default with the Merton distance-to-default model. Review of Financial Studies 21, 1339-1369.

Boudoukh, J., and Whitelaw, R., 1993. Liquidity as a choice variable: a lesson from the Japanese government bond market. Review of Financial Studies 6, 265-292.

Brunnermeier, M., Pedersen, L., 2009. Market liquidity and funding liquidity. Review of Financial Studies 22, 2201-2238.

Bushman, R., Le, A., Vasvari, F., 2009. Implied bond liquidity. Unpublished working paper, University of North Carolina at Chapel Hill and London Business School.

Campbell, J., Hentschel, L., 1992. No news is good news: An asymmetric model of changing volatility in stock returns. Journal of Financial Economics 31, 281-318.

Campbell, J., Hilscher, J., Szilagyi, J., 2008. In search of distress risk. Journal of Finance 63, 2899-2939.

Chacko, G., 2005. Liquidity risk in the corporate bond markets. Unpublished working paper, Harvard Business School. 
Chen, N., Roll, R., Ross, S., 1986. Economic forces and the stock market. Journal of Business 59, 383-403.

Chen, L., David, L., and Jason, W., 2007. Corporate yield spreads and bond liquidity. Journal of Finance 62, 119-149.

Comerton-Forde, C., Hendershott, T., Jones, C., Moulton, P., Seasholes, M., 2010. Time variation in liquidity: the role of market-maker inventories and revenues. Journal of Finance 65, 295-331.

Cox, D.R., 1970. The analysis of binomial data. Methuen \& Co., London.

de Jong, F., and Driessen, J., 2007. Liquidity risk premia in corporate bond markets. Unpublished working paper, University of Amsterdam.

Dick-Nielsen, J., Feldhutter, P., and Lando, D., 2008. Corporate bond liquidity before and after the onset of the subprime crisis. Unpublished working paper, Copenhagen Business School.

Downing, C., Underwood, S., Xing, Y., 2009. Is liquidity risk priced in the corporate bond market? Unpublished working paper, Rice University.

Edwards, A., Harris, L., Piwowar, M., 2007. Corporate bond market transaction costs and transparency. Journal of Finance 62, 1421-1451.

Elton, E., Green, C., 1998. Tax and liquidity effects in pricing government bonds. Journal of Finance 53, 1533-1562.

Elton, E., Gruber, M., Agrawal, D., Mann, C., 2001. Explaining the rate spread on corporate bonds. Journal of Finance 56, 247-277.

Estrella, A., Mishkin, F., 1998. Predicting us recessions: financial variables as leading indicators. The Review of Economics and Statistics 80, 45-61. 
Estrella, A., Gikas, H., 1991. The term structure as a predictor of real economic activity. Journal of Finance 46, 555-576.

Etula, E., 2009. Risk appetite and commodity returns. Unpublished working paper, Harvard University.

Fama, E., French, K., 1989. Business conditions and expected returns on stocks and bonds. Journal of Financial Economics 25, 23-49.

Fama, E., French, K., 1993. Common risk factors in the returns on stocks and bonds. Journal of Financial Economics 33, 3-56.

Fama, E., French, K., 1995. Size and book-to-market factors in earnings and returns. Journal of Finance 50, 131-155.

Fang, V., Noe, T., Tice, S., 2009. Stock market liquidity and firm value. Journal of Financial Economics 94, 150-169.

Friewald, N., Jankowitsch, R., Subrahmanyam, M., 2009. Illiquidity or credit deterioration: a study of liquidity in the U.S. corporate bond market during financial crises. Unpublished working paper, NYU-Stern.

Garleanu, N., Pedersen, L., 2009. Margin-based asset pricing and deviations from the law of one price. Review of Financial Studies 24, 1980-2022.

Gebhardt, W., Hvidkjaer, S., Swaminathan, B., 2005. The cross-section of expected corporate bond returns: betas or characteristics? Journal of Financial Economics $75,85-114$.

Goldstein, M., Hotchkiss, E., Sirri, E., 2007. Transparency and liquidity: a controlled experiment on corporate bonds. Review of Financial Studies 20, 235-273.

Goyenko, R., 2006. Stock and bond pricing with liquidity risk. Unpublished working paper, McGill University. 
Hamilton, J., 1989. A new approach to the economic analysis of nonstationary time series and the business cycle. Econometrica 57, 357-384.

Hamilton, J., 1994. Time series analysis. Princeton University Press, Princeton.

He, Z., Krishnamurthy, A., 2012a. Intermediary asset pricing, forthcoming. American Economic Review.

He, Z., Krishnamurthy, A., 2012b. A model of capital and crises. Review of Economic Studies 79, 735-777.

Hillegeist, S., Keating, E., Cram, D., Lundstedt, K., 2004. Assessing the probability of bankruptcy. Review of Accounting Studies 9, 5-34.

Kamara, A., 1994. Liquidity, taxes, and short-term treasury yields. Journal of Financial and Quantitative Analysis 29, 403-417.

Lin, H., Wang, J., Wu, C., 2011. Liquidity risk and the cross-section of expected corporate bond returns. Journal of Financial Economics 99, 628-650.

Longstaff, F., 2004. The flight-to-liquidity premium in us treasury bond prices. Journal of Business 77, 511-526.

Mahanti, S., Nashikkar, A., Subrahmanyam, M., Chacko, G., Mallik, G., 2008. Latent liquidity: a new measure of liquidity, with an application to corporate bonds. Journal of Financial Economics 88, 272-298.

Panyanukul, S., 2009. Liquidity risk and the pricing of sovereign bonds in emerging markets. Unpublished working paper, Warwick Business School.

Pastor, L., Stambaugh, R., 2003. Liquidity risk and expected stock returns. Journal of Political Economy 111, 642-685. 
Rietz, T., 1988. The equity risk premium: a solution. Journal of Monetary Economics 22, $117-131$.

Sadka, R., 2006. Momentum and post-earnings-announcement-drift anomalies: the role of liquidity risk. Journal of Financial Economics 80, 309-349.

Schaefer, S., Strebulaev, I., 2008. Structural models of credit risk are useful: evidence from hedge ratios on corporate bonds. Journal of Financial Economics 90, 1-19.

Shaman, P., and Stine, R., 1988. The bias of autoregressive coefficient estimators. Journal of the American Statistical Association 83, 842-848.

Shleifer, A., Vishny, R., 1992. Liquidation values and debt capacity: a market equilibrium approach. Journal of Finance 47, 1343-1366.

Stock, James H., Watson, M., 1989. New indexes of coincident and leading economic indicators, NBER Macroeconomics Annual, 351-394.

Stock, James H., Watson, M., 1999. Forecasting inflation. Journal of Monetary Economics 44, 293-335.

Stock, James H., Watson, M., 2002. Has the business cycle changed and why? NBER Macroeconomics Annual, 159-218.

Warga, A., 1998. Fixed income data base, University of Houston, Houston, Texas.

Watanabe, A., Watanabe, M, 2008. Time-varying liquidity risk and the cross section of stock returns. Review of Financial Studies 21, 2449-2486. 


\section{Table 1}

Summary statistics

Panel A provides summary statistics on bond returns by credit rating classes (in basis points) IG stands for bonds rated BBB and above. Junk stands for bonds rated BB and below. We use the Lehman Brothers Fixed Income Database for the period January 1973 to December 1996, supplemented with data from the Merrill Lynch Corporate Bond Index Database for the period January 1994 to December 2007, giving us a sample period of 1973 to 2007. Included bonds must be in the Lehman/Merrill index with at least one year to maturity. The average return for each rating group is value-weighted by the amount outstanding in that month. Returns are calculated using quoted prices or trades and matrix prices are discarded. Returns for credit rating classes are not available for some months in the sample period, but returns by IG and Junk rating class are available for all months in the sample period. Panel B provides summary statistics on bond market factors and documents the return on the two factor portfolios DEF and TERM in basis points, and summary statistics on the Silliq and the Billiq factors. The sample is from January 1973 through December 2007. The default factor (DEF) is the difference between the equally weighted return on all corporate bonds in the database with at least one year to maturity and the average return on one-year and 30-year government bonds from CRSP. The term factor (TERM) is the difference between the 30-year government bond return and the one-month T-bill return from CRSP. Silliq is the innovation in stock market illiquidity measure ILLIQ from Amihud (2002), modified by Acharya and Pedersen (2005), calculated as the residuals of an $\operatorname{AR}(2)$ process. Billiq is the innovation in bond market illiquidity using short maturity on-the-run Treasuries bid-ask spread as in Goyenko (2006), and calculated as the residuals of an $\mathrm{AR}(2)$ process. Panel C presents pairwise spearman correlations of bond market factors. Number in parentheses in Panel $\mathrm{C}$ are $p$-values for the test that the correlation coefficient equals zero.

Panel A:

\begin{tabular}{lcccccc}
\hline Credit rating & $\mathrm{N}$ & Mean & Std.dev & Median & Min & Max \\
\hline AAA & 415 & 67.2 & 134.5 & 63.0 & -535.4 & 736.8 \\
AA & 409 & 72.6 & 146.0 & 71.3 & -414.7 & 772.3 \\
A & 415 & 72.1 & 152.5 & 73.8 & -466.4 & 667.5 \\
BBB & 413 & 73.5 & 152.0 & 77.5 & -500.2 & 745.7 \\
BB & 405 & 89.2 & 167.7 & 90.8 & -670.1 & 850.0 \\
B & 405 & 99.4 & 221.7 & 108.7 & -804.0 & 1069.7 \\
CCC \& below & 369 & 160.3 & 332.0 & 148.6 & -905.0 & 1069.7 \\
IG & 420 & 67.6 & 127.3 & 63.0 & -428.3 & 735.1 \\
JUNK & 420 & 97.6 & 177.9 & 101.4 & -804.0 & 1069.7 \\
\hline
\end{tabular}

Panel B:

\begin{tabular}{lcccccc}
\hline & $\mathrm{N}$ & Mean & Std.dev & Median & Min & Max \\
\hline TERM & 420 & 17.7 & 319.6 & 19.6 & -1055.5 & 1162.5 \\
DEF & 420 & 9.5 & 113.5 & 10.6 & -625.1 & 616.9 \\
Silliq & 420 & -0.02161 & 0.16112 & -0.02248 & -0.58342 & 0.65319 \\
Billiq & 420 & -0.05087 & 0.43084 & -0.02648 & -1.55171 & 2.07333 \\
\hline
\end{tabular}


Panel $C$ :

\begin{tabular}{lcccc} 
& TERM & DEF & Silliq & Billiq \\
\hline TERM & 1 & & & \\
DEF & -0.529 & 1 & & \\
& $(0.00)$ & & & \\
Silliq & 0.041 & -0.153 & 1 & \\
& $(0.40)$ & $(0.00)$ & & \\
Billiq & -0.057 & -0.057 & 0.086 & 1 \\
& $(0.25)$ & $(0.25)$ & $(0.08)$ & \\
\hline
\end{tabular}




\section{Table 2}

Regressions of bond portfolio return on bond market factors

Panel A presents regressions of bond portfolio return on bond market factors. Bond returns for each rating group are in excess of the 30-day T-bill return. $\beta_{T}, \beta_{D}, \beta_{S i}$, and $\beta_{B i}$ are, respectively, the regression coefficients of TERM, DEF, Silliq, and Billiq, as defined in Table 1, Panel B. Bond returns are calculated as defined in Table 1, Panel A. Panel B presents the ratio of the standard deviation of returns to standard deviation of factors.

Panel A:

\begin{tabular}{lcccccccccccc}
\hline \multicolumn{1}{c}{ Coefficients } \\
\hline Rating & $\alpha$ & $\beta_{T}$ & $\beta_{D}$ & $\beta_{S i}$ & $\beta_{B i}$ & Adj-Rsq & $\alpha$ & $\beta_{T}$ & $\beta_{D}$ & $\beta_{S i}$ & $\beta_{B i}$ & $\mathrm{~N}$ \\
\hline AAA & 2.68 & 0.42 & 0.76 & 73.70 & 13.58 & 0.76 & 0.83 & 35.98 & 22.91 & 3.69 & 1.83 & 415 \\
AA & 5.68 & 0.47 & 0.81 & 61.69 & 1.81 & 0.79 & 1.68 & 38.31 & 23.27 & 2.93 & 0.23 & 409 \\
A & 3.55 & 0.50 & 0.90 & 40.39 & -1.66 & 0.82 & 1.12 & 43.67 & 27.42 & 2.05 & -0.23 & 415 \\
BBB & 3.72 & 0.47 & 0.97 & 17.06 & -11.41 & 0.75 & 0.97 & 33.83 & 24.42 & 0.72 & -1.29 & 413 \\
BB & 14.91 & 0.38 & 0.98 & -90.15 & -57.28 & 0.51 & 2.47 & 17.43 & 15.85 & -2.38 & -4.16 & 405 \\
B & 23.61 & 0.35 & 0.99 & -193.55 & -70.07 & 0.30 & 2.49 & 10.25 & 10.18 & -3.26 & -3.23 & 405 \\
CCC \& below & 84.52 & 0.21 & 0.89 & -328.70 & -63.19 & 0.11 & 5.04 & 3.47 & 5.33 & -3.16 & -1.70 & 369 \\
\hline
\end{tabular}

Panel B:

\begin{tabular}{lcccc}
\hline & \multicolumn{4}{c}{ Ratio to $\sigma_{\text {returns }}$ of } \\
Rating & $\sigma_{D}$ & $\sigma_{D}$ & $\sigma_{S i}$ & $\sigma_{B i}$ \\
\hline AAA & $99.48 \%$ & $64.11 \%$ & $8.83 \%$ & $4.35 \%$ \\
AA & $101.88 \%$ & $67.96 \%$ & $7.39 \%$ & $0.58 \%$ \\
A & $104.88 \%$ & $75.53 \%$ & $4.84 \%$ & $0.53 \%$ \\
BBB & $98.60 \%$ & $81.45 \%$ & $2.04 \%$ & $3.65 \%$ \\
BB & $72.03 \%$ & $82.30 \%$ & $10.80 \%$ & $18.34 \%$ \\
B & $50.36 \%$ & $83.31 \%$ & $23.18 \%$ & $22.44 \%$ \\
CCC \& below & $19.86 \%$ & $75.35 \%$ & $39.36 \%$ & $20.24 \%$ \\
\hline
\end{tabular}




\section{Table 3}

Regime-switching model for bond returns

Panel A provides the estimates of the following model.

Investment-grade returns (in excess of the 30-day T-bill return):

Regime 1: $r_{I G, t}=\alpha_{I G}^{1}+\beta_{I G, T}^{1} T E R M_{t}+\beta_{I G, D}^{1} D E F_{t}+\beta_{I G, S i}^{1} S_{i l l i q}+$

$$
\beta_{I G, B i}^{1} \text { Billiq }_{t}+\epsilon_{I G, t}^{1}
$$

Regime 2: $r_{I G, t}=\alpha_{I G}^{2}+\beta_{I G, T}^{2} T E R M_{t}+\beta_{I G, D}^{2} D E F_{t}+\beta_{I G, S i}^{2} S_{i l l i q}+$

$$
\beta_{I G, B i}^{2} \text { Billiq }_{t}+\epsilon_{I G, t}^{2}
$$

Junk grade returns (in excess of the 30-day T-bill return):

Regime 1: $r_{J u n k, t}=\alpha_{\text {Junk }}^{1}+\beta_{\text {Junk }, T}^{1} T E R M_{t}+\beta_{\text {Junk }, D}^{1} D E F_{t}+\beta_{J u n k, S i}^{1}$ Silliq $_{t}+$

$$
\beta_{\text {Junk,Bi}}^{1} \text { Billiq }_{t}+\epsilon_{\text {Junk,t }}^{1}
$$

Regime 2: $r_{\text {Junk }, t}=\alpha_{\text {Junk }}^{2}+\beta_{\text {Junk }, T}^{2} T E R M_{t}+\beta_{\text {Junk }, D}^{2} D E F_{t}+\beta_{J u n k, S i}^{2}$ Silliq $_{t}+$

$$
\beta_{\text {Junk,Bi}}^{2} \text { Billiq }_{t}+\epsilon_{J u n k, t}^{2}
$$

Regime Dependent Variance-Covariance Matrix $\left(s_{t}=1,2\right)$ :

$$
\Omega_{s_{t}}=\left(\begin{array}{cc}
\sigma_{I G, s_{t}}^{2} & \rho_{s_{t}} \sigma_{I G, s_{t}} \sigma_{J u n k, s_{t}} \\
\rho_{s_{t}} \sigma_{I G, s_{t}} \sigma_{J u n k, s_{t}} & \sigma_{\text {Junk }, s_{t}}^{2}
\end{array}\right)
$$

Markov switching probability for state transition:

$P\left(s_{t}=1 \mid s_{t-1}=1\right)=p$

$P\left(s_{t}=2 \mid s_{t-1}=2\right)=q$

In Panels $\mathrm{B}$ and $\mathrm{C}$, we test whether the conditional model, with the factor coefficients varying between regimes, is significantly different from the unconditional model with constant coefficients. The null hypothesis about the coefficients is $H_{0}: L \beta=c$ where $L$ is a matrix of coefficients for the hypotheses and $c$ is a vector of constants. The Wald chi-squared statistic for testing $H_{0}$ is computed as $\chi_{W}^{2}=$ $(L \hat{\beta}-c)^{\prime}\left[L \hat{V}(\hat{\beta}) L^{\prime}\right]^{-1}(L \hat{\beta}-c)$. Under $H_{0}, \chi_{W}^{2}$ has an asymptotic chi-squared distribution with $r$ degrees of freedom where $r$ is the rank of $L$ and $V$ the variance-covariance matrix of the coefficients. In Panel $\mathrm{D}$ we assess the in sample accuracy of the regime-switching model. Panel D uses the regime-switching model estimated in Panel A to obtain estimates of investment-grade (IG) and junk grade bond returns in each regime and compares it against the actual realizations. We also estimate an unconditional model over the entire sample (1973-2007) and obtain the predictions. Panels show the regression of the actual bond returns against the predicted bond returns with a test of the slope coefficient $=1.0$ and the intercept being zero. $* * *, * *, *$ Indicate significance at the $1 \%, 5 \%$, and $10 \%$ levels, respectively. Numbers in parentheses under the coefficients are standard errors. 
Panel A: Estimation of a Markov regime-switching model

\begin{tabular}{|c|c|c|c|c|c|c|}
\hline \multicolumn{7}{|l|}{ Regime 1} \\
\hline & \multicolumn{2}{|c|}{ Investment grade } & \multicolumn{2}{|c|}{ Junk grade } & \multicolumn{2}{|c|}{ Parameters } \\
\hline & Coeff & $t$-Stat & Coeff & $t$-Stat & & \\
\hline Constant & 2.34 & 1.36 & 27.21 & 4.72 & $p$ & 0.96 \\
\hline TERM & 0.35 & 44.38 & 0.28 & 12.56 & $q$ & 0.93 \\
\hline DEF & 0.37 & 12.06 & 1.08 & 10.07 & $\rho_{s_{t}=1}$ & 0.10 \\
\hline Silliq & 13.95 & 1.21 & -68.89 & -2.08 & $\rho_{s_{t}=2}$ & -0.40 \\
\hline Billiq & -2.40 & -0.49 & -14.11 & -0.91 & & \\
\hline$\sigma_{i}$ & 24.31 & & 82.96 & & & \\
\hline \multicolumn{7}{|l|}{ Regime 2} \\
\hline & \multicolumn{2}{|c|}{ Investment grade } & \multicolumn{2}{|c|}{ Junk grade } & & \\
\hline & Coeff & $t$-Stat & Coeff & $t$-Stat & & \\
\hline Constant & 7.21 & 1.59 & 22.07 & 1.44 & & \\
\hline TERM & 0.52 & 29.92 & 0.46 & 7.56 & & \\
\hline DEF & 0.97 & 26.76 & 1.06 & 8.78 & & \\
\hline Silliq & 64.77 & 3.13 & -195.19 & -4.31 & & \\
\hline Billiq & 20.69 & 2.37 & -65.76 & -2.37 & & \\
\hline$\sigma_{i}$ & 53.18 & & 188.23 & & & \\
\hline
\end{tabular}

Panel B: Wald tests for differences in coefficients between regime 1 and regime 2 Investment grade Junk grade

\begin{tabular}{lcccc} 
& Chi-sq & $p$-Value & Chi-sq & $p$-Value \\
\hline TERM \& DEF & 177.18 & 0.00 & 11.61 & 0.00 \\
Liquidity & 10.20 & 0.01 & 8.46 & 0.01 \\
Constant & 0.99 & 0.99 & 0.10 & 0.76 \\
TERM & 89.50 & 0.00 & 7.37 & 0.01 \\
DEF & 167.72 & 0.00 & 0.01 & 0.92 \\
Silliq & 4.44 & 0.03 & 5.93 & 0.01 \\
Billiq & 5.58 & 0.02 & 2.53 & 0.10 \\
\hline
\end{tabular}

Panel C: Wald tests for differences in coefficients between junk and IG

$$
\text { Regime } 1 \quad \text { Regime } 2
$$

\begin{tabular}{lcccc} 
& Chi-sq & $p$-Value & Chi-sq & $p$-Value \\
\hline TERM \& DEF & 97.02 & 0.00 & 3.79 & 0.15 \\
Liquidity & 6.42 & 0.04 & 35.81 & 0.00 \\
Constant & 18.28 & 0.00 & 0.71 & 0.40 \\
TERM & 11.00 & 0.00 & 0.86 & 0.36 \\
DEF & 41.81 & 0.00 & 0.52 & 0.47 \\
Silliq & 5.87 & 0.01 & 28.22 & 0.00 \\
Billiq & 0.59 & 0.44 & 7.54 & 0.00 \\
\hline Log likelihood & -4676.81 & & & \\
Sample period & $1973: 01-2007: 12$ & & & \\
\hline
\end{tabular}


Panel D: In-sample accuracy of the regime-switching model.

Constant.

\begin{tabular}{cccr}
\multicolumn{3}{c}{ Regime 1: Actual returns } \\
\hline \multicolumn{3}{c}{ IG } & \multicolumn{2}{c}{ Junk } \\
\hline-0.81 & -2.09 & -0.47 & 7.66 \\
$(1.56)$ & $(1.89)$ & $(5.79)$ & $(5.73)$
\end{tabular}

Predicted - Regime 1 parameters $\quad 1.02^{* * *}$

(0.02)

Predicted - Unconditional parameters

$0.87^{* * *}$

$(0.02)$

Predicted - Regime 1 parameters

$$
\begin{gathered}
1.02^{* * *} \\
(0.06)
\end{gathered}
$$

Predicted - Unconditional parameters

\begin{tabular}{|c|c|c|c|c|}
\hline$\overline{\text { Obs. }}$ & 276 & 276 & 276 & 276 \\
\hline $\operatorname{Adj} R^{2}$ & 0.94 & 0.91 & 0.52 & 0.49 \\
\hline$F$-test if & 1.05 & 66.51 & 0.13 & 10.81 \\
\hline \multirow[t]{3}{*}{ Slope $=1.0(p$-Value $)$} & $(0.307)$ & $(0.000)$ & $(0.722)$ & $(0.001)$ \\
\hline & \multicolumn{4}{|c|}{ Regime 2: Actual returns } \\
\hline & \multicolumn{2}{|c|}{ IG } & \multicolumn{2}{|c|}{ Junk } \\
\hline Constant. & $\begin{array}{l}1.06 \\
(4.57)\end{array}$ & $\begin{array}{l}5.16 \\
(4.56)\end{array}$ & $\begin{array}{l}-3.57 \\
(17.04)\end{array}$ & $\begin{array}{l}-8.21 \\
(17.48)\end{array}$ \\
\hline Predicted - Regime 2 parameters & $\begin{array}{c}1.02^{* * *} \\
(0.03)\end{array}$ & & & \\
\hline Predicted - Unconditional parameters & & $\begin{array}{c}1.25^{* * *} \\
(0.04)\end{array}$ & & \\
\hline Predicted - Regime 2 parameters & & & $\begin{array}{c}1.03^{* * *} \\
(0.10)\end{array}$ & \\
\hline Predicted - Unconditional parameters & & & & $\begin{array}{c}1.18^{* * *} \\
(0.12)\end{array}$ \\
\hline Obs. & 144 & 144 & 144 & 144 \\
\hline $\operatorname{Adj} R^{2}$ & 0.88 & 0.88 & 0.41 & 0.39 \\
\hline$F$-test if & 0.25 & 40.77 & 0.11 & 2.29 \\
\hline Slope $=1.0(p$-Value $)$ & $(0.620)$ & $(0.000)$ & $(0.742)$ & $(0.132)$ \\
\hline
\end{tabular}

$\begin{array}{cc}1.02^{* * *} & \\ (0.06) & \\ & 0.83^{* * *} \\ & (0.05)\end{array}$


Table 4

Explaining the probability of regime 2 (stress regime) with macroeconomic, financial market, and bank balance-sheet variables

This table presents OLS and logit estimates of the probability of being in regime 2 as a function of macroeconomic and financial market variables. The OLS regression uses as dependent variable the probability of being in regime 2 in any month, that is estimated along with the regime-switching model in Table 3. The probability undergoes a logit transformation to map it into the real line, with a constant correction term following Cox (1970, p. 33), to accommodate it being bounded between zero and one. The dependent variable in the logit model is a dummy variable that equals one if the probability of being in regime 2 is greater than $70 \%$. Odd (even) numbered specifications are OLS (logit) estimations, where the explanatory variables are lagged one period. NBER recession is a dummy variable that equals one for NBER recession dates. $S W$ index is the Stock and Watson $(1989,2002)$ recession index with positive numbers indicating growth above trend. Prob(Recession) - Hamilton is the result of the Markov switching model for the quarterly growth rate in U.S. GNP. We use these models to estimate the probability of being in regime 1 interpreted by Hamilton (1989) as the recession regime greater than 70\%. Negative market return is a dummy variable that equals one for three consecutive months of negative market return (the CRSP value-weighted return with dividends). Business conditions index, is based on the framework developed in Aruoba, Diebold, and Scotti (2009). The average value of the index is zero, with bigger positive (negative) values indicating better- (worse)-than-average conditions. Paper bill spread is the difference between the yield on the three-month nonfinancial commercial paper rate and the three-month T-bill secondary market rate. TED spread is the difference between the yield on the three-month Euro $\$$ deposit rate and the three-month T-bill secondary market rate, orthogonal to the paper bill spread. Equity volatility is the square root of the monthly average squared daily returns on the CRSP value-weighted index with dividends. EE measure is the growth in broker-dealer balance sheet (relative to households) over the previous 12 months as calculated by Etula (2009). The sample period is January 1973 -December 2007. $* * *, * * *$ Indicate significance at the $1 \%, 5 \%$, and $10 \%$ levels, respectively. Numbers in parentheses under the coefficients are standard errors.

\begin{tabular}{|c|c|c|c|c|c|c|c|c|}
\hline & (1) & $(2)$ & $(3)$ & (4) & (5) & (6) & (7) & (8) \\
\hline Constant. & $\begin{array}{c}-1.92^{* * *} \\
(0.24)\end{array}$ & $\begin{array}{c}-1.03^{* * *} \\
(0.12)\end{array}$ & $\begin{array}{c}-1.11^{* * *} \\
(0.22)\end{array}$ & $\begin{array}{c}-0.70^{* * *} \\
(0.11)\end{array}$ & $\begin{array}{c}-2.69^{* * *} \\
(0.28)\end{array}$ & $\begin{array}{c}-1.40^{* * *} \\
(0.16)\end{array}$ & $\begin{array}{c}-1.92^{* * *} \\
(0.33)\end{array}$ & $\begin{array}{c}-1.06^{* * *} \\
(0.17)\end{array}$ \\
\hline $\mathrm{NBER}$ recession $_{t-1}$ & $\begin{array}{c}5.88^{* * *} \\
(0.50)\end{array}$ & $\begin{array}{c}2.62^{* * *} \\
(0.37)\end{array}$ & & & & & & \\
\hline SW index ${ }_{t-1}$ & & & $\begin{array}{c}-1.69^{* * *} \\
(0.19)\end{array}$ & $\begin{array}{c}-0.76^{* * *} \\
(0.13)\end{array}$ & & & & \\
\hline Prob(Recession)-Hamilton ${ }_{t-1}$ & & & & & $\begin{array}{c}4.71^{* * *} \\
(0.59)\end{array}$ & $\begin{array}{c}2.01^{* * *} \\
(0.28)\end{array}$ & & \\
\hline Negative market return $_{t-1}$ & & & & & & & $\begin{array}{c}3.12^{* * *} \\
(0.84)\end{array}$ & $\begin{array}{c}1.78^{* * *} \\
(0.48)\end{array}$ \\
\hline Business conditions index ${ }_{t-1}$ & & & & & & & $\begin{array}{c}-1.81^{* * *} \\
(0.23)\end{array}$ & $\begin{array}{c}-0.93^{* * *} \\
(0.17)\end{array}$ \\
\hline Paper bill $\operatorname{spread}_{t-1}$ & & & & & & & $\begin{array}{r}0.01^{* *} \\
(0.004)\end{array}$ & $\begin{array}{c}0.004^{* *} \\
(0.002)\end{array}$ \\
\hline TED $\operatorname{spread}_{t-1}$ & & & & & & & $\begin{array}{c}0.03^{* * *} \\
(0.005)\end{array}$ & $\begin{array}{c}0.01^{* * *} \\
(0.003)\end{array}$ \\
\hline Obs. & 419 & 419 & 419 & 419 & 419 & 419 & 419 & 419 \\
\hline $\operatorname{Adj} R^{2} /$ PseudoR $(\%)$ & 18 & 13 & 11 & 8 & 14 & 10 & 23 & 16 \\
\hline
\end{tabular}




\begin{tabular}{|c|c|c|c|c|c|c|}
\hline & (9) & $(10)$ & $(11)$ & $(12)$ & (13) & (14) \\
\hline Const. & $\begin{array}{c}-4.57^{* * *} \\
(1.02)\end{array}$ & $\begin{array}{c}-2.50^{* * *} \\
(0.40)\end{array}$ & $\begin{array}{c}-4.69^{* * *} \\
(0.79)\end{array}$ & $\begin{array}{c}-2.54^{* * *} \\
(0.40)\end{array}$ & $\begin{array}{c}-4.75^{* * *} \\
(0.79)\end{array}$ & $\begin{array}{c}-2.62^{* * *} \\
(0.41)\end{array}$ \\
\hline NBER recession $_{t-1}$ & & & $\begin{array}{l}1.43^{*} \\
(0.84)\end{array}$ & $\begin{array}{l}1.20^{*} \\
(0.61)\end{array}$ & & \\
\hline $\mathrm{SW}$ index $_{t-1}$ & & & $\begin{array}{l}0.12 \\
(0.33)\end{array}$ & $\begin{array}{l}0.06 \\
(0.23)\end{array}$ & $\begin{array}{l}0.006 \\
(0.32)\end{array}$ & $\begin{array}{l}-0.03 \\
(0.23)\end{array}$ \\
\hline Prob(Recession)-Hamilton ${ }_{t-1}$ & & & $\begin{array}{l}1.08 \\
(0.67)\end{array}$ & $\begin{array}{c}1.01^{* *} \\
(0.48)\end{array}$ & $\begin{array}{c}1.32^{* *} \\
(0.65)\end{array}$ & $\begin{array}{c}1.21^{* *} \\
(0.47)\end{array}$ \\
\hline Negative market return $_{t-1}$ & & & $\begin{array}{l}0.85 \\
(0.93)\end{array}$ & $\begin{array}{l}0.85 \\
(0.59)\end{array}$ & $\begin{array}{l}10.11 \\
(0.90)\end{array}$ & $\begin{array}{c}10.04^{*} \\
(0.60)\end{array}$ \\
\hline Business conditions index ${ }_{t-1}$ & & & $\begin{array}{c}-0.99^{* * *} \\
(0.35)\end{array}$ & $\begin{array}{c}-0.47^{*} \\
(0.28)\end{array}$ & $\begin{array}{c}-10.13^{* * *} \\
(0.35)\end{array}$ & $\begin{array}{c}-0.60^{* *} \\
(0.28)\end{array}$ \\
\hline Paper bill spread $t-1$ & & & $\begin{array}{l}0.002 \\
(0.005)\end{array}$ & $\begin{array}{c}-0.005 \\
(0.004)\end{array}$ & $\begin{array}{l}0.004 \\
(0.005)\end{array}$ & $\begin{array}{c}-0.002 \\
(0.003)\end{array}$ \\
\hline TED $\operatorname{spread}_{t-1}$ & & & $\begin{array}{c}0.03^{* * *} \\
(0.005)\end{array}$ & $\begin{array}{c}0.01^{* * *} \\
(0.004)\end{array}$ & $\begin{array}{c}0.03^{* * *} \\
(0.005)\end{array}$ & $\begin{array}{c}0.01^{* * *} \\
(0.004)\end{array}$ \\
\hline EE measure previousyear & $\begin{array}{l}-229.49^{* * *} \\
\quad(76.29)\end{array}$ & $\begin{array}{l}-245.46^{* * *} \\
\quad(56.70)\end{array}$ & $\begin{array}{l}-200.11^{* * *} \\
(58.32)\end{array}$ & $\begin{array}{l}-236.90^{* * *} \\
(46.42)\end{array}$ & $\begin{array}{l}-206.00^{* * *} \\
(57.80)\end{array}$ & $\begin{array}{l}-236.09^{* * *} \\
(46.97)\end{array}$ \\
\hline Equity volatility $_{t-1}$ & $\begin{array}{c}93.82^{* * *} \\
(26.44)\end{array}$ & $\begin{array}{c}53.44^{* * *} \\
(10.45)\end{array}$ & $\begin{array}{c}80.39^{* * *} \\
(20.91)\end{array}$ & $\begin{array}{c}49.93^{* * *} \\
(9.69)\end{array}$ & $\begin{array}{c}80.53^{* * *} \\
(20.73)\end{array}$ & $\begin{array}{c}50.01^{* * *} \\
(9.89)\end{array}$ \\
\hline $\begin{array}{l}\text { Equity volatility }_{t-1} * \\
\text { EE measure }_{\text {previousyear }}\end{array}$ & $\begin{array}{c}5099.01^{* * *} \\
(1787.59)\end{array}$ & $\begin{array}{c}5009.99^{* * *} \\
(1336.16)\end{array}$ & $\begin{array}{c}4248.32^{* * *} \\
\quad(1336.11)\end{array}$ & $\begin{array}{l}4011.05^{* * *} \\
\quad(964.58)\end{array}$ & $\begin{array}{c}4364.55^{* * *} \\
\quad(1314.77)\end{array}$ & $\begin{array}{l}4029.97^{* * *} \\
\quad(996.73)\end{array}$ \\
\hline Obs. & 419 & 419 & 419 & 419 & 419 & 419 \\
\hline $\operatorname{Adj}^{2} /$ PseudoR $(\%)$ & 28 & 23 & 44 & 36 & 43 & 35 \\
\hline
\end{tabular}




\section{Table 5}

Estimation of the likelihood of regime 2 (stress regime)-out-of-sample tests

This table tests the performance of the probability of regime 2, as predicted by the economic model in Table 4, when compared to the probability of regime 2 obtained from the Markov regime-switching model of Table 3. First, we estimate model (14) of Table 4 using only the data for January 1973 - December 1989. Using these estimates, we predict the probability of being in regime 2 for January 1990, then we roll forward every month and repeat the process until we estimate the probability of regime 2 for all months during January 1990 - December 2007. We present a logit estimation of the probability of being in regime 2 as a function of the predicted Prob(Regime 2) as the independent variable. The dependent variable is a dummy variable that equals one if the probability of being in regime 2, obtained from the estimates in Table 3, is greater than $70 \%$ following the cutoff level in Hamilton (1989). We also present a figure that displays the ROC (Receiver Operating Characteristic) curve to assess the accuracy of this logit model to predict regime 2 . In the $Y$-axis we plot the true positive rate, the proportion of actual regime 2 months correctly classified by the model. In the $X$-axis we plot the false positive rate, the proportion of non regime 2 months that are incorrectly classified as regime 2 months by the model. The diagonal represents random guess. Points above the diagonal indicate good classification results, with the total area under the curve relative to the area of the square measuring the accuracy of the model. $* * *, * *, *$ Indicate significance at the $1 \%, 5 \%$, and $10 \%$ levels, respectively. Numbers in parentheses under the coefficients are standard errors.

Constant

Regime 2 (as per regime-switching model 1990 - 2007)

\begin{tabular}{lc} 
Constant & $-1.78^{* * *}$ \\
& $(0.24)$ \\
Predicted Prob(Regime 2) & $5.77^{* * *}$ \\
& $(0.94)$ \\
\hline Obs. & 216 \\
PseudoR $R^{2}(\%)$ & 27 \\
Area under the ROC curve $(\%)$ & 88.81 \\
\hline
\end{tabular}






\section{Table 6}

Out-of-sample predictions during the financial crisis years, 2008 - 2009.

Panel A shows the estimated probability of regime 2, obtained from specification (14) in Table 4, using the economic time-series for December 2007 - November 2009 (the predictive economic series are lagged one month). Panel B presents the regression of the actual bond returns on the predicted bond returns (in excess of the 30-day T-bill return) for the years 2008 - 2009 in basis points. We use the data on iShares investment-grade and high-yield bond indices to compute the bond returns for these years. The table presents the intercepts and slope coefficients for both investment-grade and junk grade bonds, with a test of the slope coefficient $=1.0$. To predict bond returns for 2008 and 2009, we proceed as follows: First, we predict the probability as explained in Panel A. Next, we weight the prediction of bond returns itself for 2008 - 2009 from the regime-switching model of Table 3 by the respective regime probabilities to obtain the predicted bond returns (in excess of the 30-day T-bill return). Numbers in parentheses under the coefficients are standard errors. $* * *, * *, *$ Indicate significance at the $1 \%, 5 \%$, and $10 \%$ levels, respectively.

Panel A

\begin{tabular}{lclc}
\hline Date & $\begin{array}{c}\text { Predicted } \\
\text { Prob(Regime 2) }\end{array}$ & Date & $\begin{array}{c}\text { Predicted } \\
\text { Prob(Regime 2) }\end{array}$ \\
\hline 200801 & 0.53 & 200901 & 0.97 \\
200802 & 0.97 & 200902 & 0.91 \\
200803 & 0.85 & 200903 & 0.66 \\
200804 & 0.98 & 200904 & 0.002 \\
200805 & 0.72 & 200905 & 0.40 \\
200806 & 0.61 & 200906 & 0.66 \\
200807 & 0.81 & 200907 & 0.89 \\
200808 & 0.89 & 200908 & 0.42 \\
200809 & 0.94 & 200909 & 0.70 \\
200810 & 1.00 & 200910 & 0.82 \\
200811 & 1.00 & 200911 & 0.25 \\
200812 & 1.00 & 200912 & 0.65 \\
\hline
\end{tabular}

Panel B

\begin{tabular}{lcc}
\hline & $\begin{array}{c}\text { Actual IG } \\
\text { returns }\end{array}$ & $\begin{array}{c}\text { Actual junk } \\
\text { returns }\end{array}$ \\
\cline { 2 - 3 } Constant & 4.65 & 51.15 \\
Predicted IG returns & $(42.93)$ & $(66.82)$ \\
Predicted junk returns & $0.839^{* * *}$ & \\
& $(0.098)$ & $0.862^{* * *}$ \\
Obs. & & $0.102)$ \\
$R^{2}(\%)$ & 24 & 24 \\
$F$-test if & 77 & 76 \\
Slope $=1.0(p$-value $)$ & 2.70 & 1.84 \\
\hline
\end{tabular}




\section{Table 7}

Regime-switching model for stock returns

Panel A provides the estimates of the following model.

Low book-to-market stock returns (in excess of the risk-free rate):

Regime 1: $r_{\text {Low }, t}=\alpha_{\text {Low }}^{1}+\beta_{\text {Low }, R m t}^{1}\left(R_{m, t}-R_{f, t}\right)+\beta_{\text {Low }, T}^{1} T E R M_{t}+\beta_{\text {Low }, D}^{1} D E F_{t}+\beta_{\text {Low }, \text { Sit }}^{1}$ Silliq $_{t}+$ $\beta_{\text {Low }, \text { Bit }}^{1}$ Billiq $_{t}+\epsilon_{\text {Low }, t}^{1}$

Regime 2: $r_{\text {Low }, t}=\alpha_{\text {Low }}^{2}+\beta_{\text {Low }, R m t}^{2}\left(R_{m, t}-R_{f, t}\right)+\beta_{\text {Low }, T}^{2} T E R M_{t}+\beta_{\text {Low }, D}^{2} D E F_{t}+\beta_{\text {Low }, \text { Sit }}^{2}$ Silliq $_{t}+$ $\beta_{\text {Low }, \text { Bit }}^{2}$ Billiq $_{t}+\epsilon_{\text {Low }, t}^{2}$

High book-to-market stock returns (in excess of the risk-free rate):

Regime 1: $r_{H i g h, t}=\alpha_{H i g h}^{1}+\beta_{H i g h, R m t}^{1}\left(R_{m, t}-R_{f, t}\right)+\beta_{H i g h, T}^{1} T E R M_{t}+\beta_{H i g h, D}^{1} D E F_{t}+\beta_{H i g h, S i t}^{1} S_{i l l i q}+$ $\beta_{\text {High,Bit }}^{1}$ Billiq $_{t}+\epsilon_{\text {High }, t}^{1}$

Regime 2: $r_{H i g h, t}=\alpha_{H i g h}^{2}+\beta_{H i g h, R m t}^{2}\left(R_{m, t}-R_{f, t}\right)+\beta_{H i g h, T}^{2} T E R M_{t}+\beta_{H i g h, D}^{2} D E F_{t}+\beta_{H i g h, S i t}^{2} S_{i l l i q}+$ $\beta_{\text {High,Bit }}^{2}$ Billiq $_{t}+\epsilon_{\text {High }, t}^{2}$

Regime Dependent Variance-Covariance Matrix $\left(s_{t}=1,2\right)$ :

$$
\Omega_{s_{t}}=\left(\begin{array}{cc}
\sigma_{\text {Low }, s_{t}}^{2} & \rho_{s_{t}} \sigma_{\text {Low, } s_{t}} \sigma_{H i g h, s_{t}} \\
\rho_{s_{t}} \sigma_{\text {Low }, s_{t}} \sigma_{\text {High }, s_{t}} & \sigma_{\text {High }, s_{t}}^{2}
\end{array}\right)
$$

Markov switching probability for state transition:

$P\left(s_{t}=1 \mid s_{t-1}=1\right)=p$

$P\left(s_{t}=2 \mid s_{t-1}=2\right)=q$

In Panels $\mathrm{B}$ and $\mathrm{C}$ we test whether the conditional model, with the factor coefficients varying between regimes, is significantly different from the unconditional model with constant coefficients. The null hypothesis about the coefficients is $H_{0}: L \beta=c$ where $L$ is a matrix of coefficients for the hypotheses and $c$ is a vector of constants. The Wald chi-squared statistic for testing $H_{0}$ is computed as $\chi_{W}^{2}=$ $(L \hat{\beta}-c)^{\prime}\left[L \hat{V}(\hat{\beta}) L^{\prime}\right]^{-1}(L \hat{\beta}-c)$. Under $H_{0}, \chi_{W}^{2}$ has an asymptotic chi-squared distribution with $r$ degrees of freedom where $r$ is the rank of $L$ and $V$ the variance-covariance matrix of the coefficients. Low and high book-to-market stock returns is the return on the lowest and highest quintiles sorted by book-to-market ratio, and data are obtained from Ken French's data library. 


\begin{tabular}{|c|c|c|c|c|c|c|}
\hline \multicolumn{7}{|c|}{$\begin{array}{l}\text { Panel A: Estimation of a Markov regime-switching model for stocks } \\
\text { Regime } 1\end{array}$} \\
\hline & \multicolumn{2}{|c|}{ Low BM } & \multicolumn{2}{|c|}{ High BM } & \multicolumn{2}{|c|}{ Parameters } \\
\hline & Coeff & $t$-Stat & Coeff & $t$-Stat & & \\
\hline Constant & -71.88 & -7.95 & -5.17 & -0.43 & $p$ & 0.957 \\
\hline$\left(R_{m}-R_{f}\right)$ & 113.44 & 50.65 & 86.20 & 26.69 & $q$ & 0.897 \\
\hline TERM & -0.07 & -2.11 & 0.05 & 1.28 & $\rho_{s_{t}=1}$ & -0.650 \\
\hline $\mathrm{DEF}$ & -0.35 & -2.89 & 0.36 & 2.04 & $\rho_{s_{t}=2}$ & -0.496 \\
\hline Silliq & 83.38 & 1.01 & -54.92 & -0.72 & & \\
\hline Billiq & 55.15 & 3.11 & -65.46 & -2.63 & & \\
\hline$\sigma_{i}$ & 117.50 & & 156.09 & & & \\
\hline \multicolumn{7}{|l|}{ Regime 2} \\
\hline & \multicolumn{2}{|c|}{ Low BM } & \multicolumn{2}{|c|}{ High BM } & & \\
\hline & Coeff & $t$-Stat & Coeff & $t$-Stat & & \\
\hline Constant & -49.15 & -1.42 & -12.76 & -0.31 & & \\
\hline$\left(R_{m}-R_{f}\right)$ & 107.66 & 33.70 & 82.79 & 12.83 & & \\
\hline TERM & -0.03 & -0.38 & 0.16 & 1.17 & & \\
\hline $\mathrm{DEF}$ & -0.16 & -1.18 & 0.50 & 1.77 & & \\
\hline Silliq & 73.62 & 1.70 & -242.21 & -4.20 & & \\
\hline Billiq & 6.30 & 0.18 & -88.32 & -1.48 & & \\
\hline$\sigma_{i}$ & 179.18 & & 366.86 & & & \\
\hline
\end{tabular}

Panel B: Wald tests for differences in coefficients between regime 1 and regime 2

$$
\text { Low BM High BM }
$$

\begin{tabular}{lcccc} 
& Chi-sq & $p$-Value & Chi-sq & $p$-Value \\
\hline Constant & 0.33 & 0.57 & 0.03 & 0.87 \\
$R_{m}-R_{f}$ & 1.93 & 0.17 & 0.19 & 0.66 \\
TERM & 0.25 & 0.62 & 0.49 & 0.48 \\
DEF & 1.07 & 0.30 & 0.14 & 0.71 \\
Silliq & 0.01 & 0.92 & 5.35 & 0.02 \\
Billiq & 1.45 & 0.23 & 0.18 & 0.67 \\
\hline
\end{tabular}

Panel C: Wald tests for differences in coefficients between high BM and low BM

$$
\text { Regime } 1 \quad \text { Regime } 2
$$

\begin{tabular}{lcccc} 
& Chi-sq & $p$-Value & Chi-sq & $p$-Value \\
\hline Constant & 11.69 & 0.00 & 0.26 & 0.61 \\
$R_{m}-R_{f}$ & 30.26 & 0.00 & 8.82 & 0.00 \\
TERM & 3.42 & 0.06 & 1.18 & 0.28 \\
DEF & 6.46 & 0.01 & 3.26 & 0.07 \\
Silliq & 0.83 & 0.36 & 22.12 & 0.00 \\
Billiq & 9.92 & 0.00 & 1.24 & 0.27 \\
\hline Log likelihood & -5421.65 & & & \\
Sample period & $1973: 01-2007: 12$ & & & \\
\hline
\end{tabular}




\section{Table 8}

Explaining the probability of regime 2 (stress regime) from the stock returns model with macroeconomic, financial market, and bank balance-sheet variables

This table presents OLS and logit estimates of the probability of being in regime 2 as a function of macroeconomic and financial market variables. The OLS regression uses as dependent variable the probability of being in regime 2 in any month, that is estimated along with the regime-switching model in Table 7. The probability undergoes a logit transformation to map it into the real line, with a constant correction term following Cox (1970, p. 33), to accommodate it being bounded between zero and one. The dependent variable in the logit model is a dummy variable that equals one if the probability of being in regime 2 is greater than 70\%. Odd (even) numbered specifications are OLS (logit) estimations, where the explanatory variables are lagged one period. NBER recession is a dummy variable that equals one for NBER recession dates. $S W$ index is the Stock and Watson $(1989,2002)$ recession index with positive numbers indicating growth above trend. Prob(Recession) - Hamilton is the result of the Markov switching model for the quarterly growth rate in U.S. GNP. We use these models to estimate the probability of being in regime 1 interpreted by Hamilton (1989) as the recession regime greater than 70\%. Negative market return is a dummy variable that equals one for three consecutive months of negative market return (the CRSP value-weighted return with dividends). Business conditions index, is based on the framework developed in Aruoba, Diebold, and Scotti (2009). The average value of the index is zero, with bigger positive (negative) values indicating better- (worse)-than-average conditions. Paper bill spread is the difference between the yield on the three-month nonfinancial commercial paper rate and the three-month T-bill secondary market rate. TED spread is the difference between the yield on the three-month Euro $\$$ deposit rate and the three-month T-bill secondary market rate, orthogonal to the paper bill spread. Equity volatility is the square root of the monthly average squared daily returns on the CRSP value-weighted index with dividends. EE measure is the growth in broker-dealer balance sheet (relative to households) over the previous 12 months as calculated by Etula (2009). The sample period is January $1973-$ December 2007. $* * *, * *, *$ Indicate significance at the $1 \%, 5 \%$, and $10 \%$ levels, respectively. Numbers in parentheses under the coefficients are standard errors.

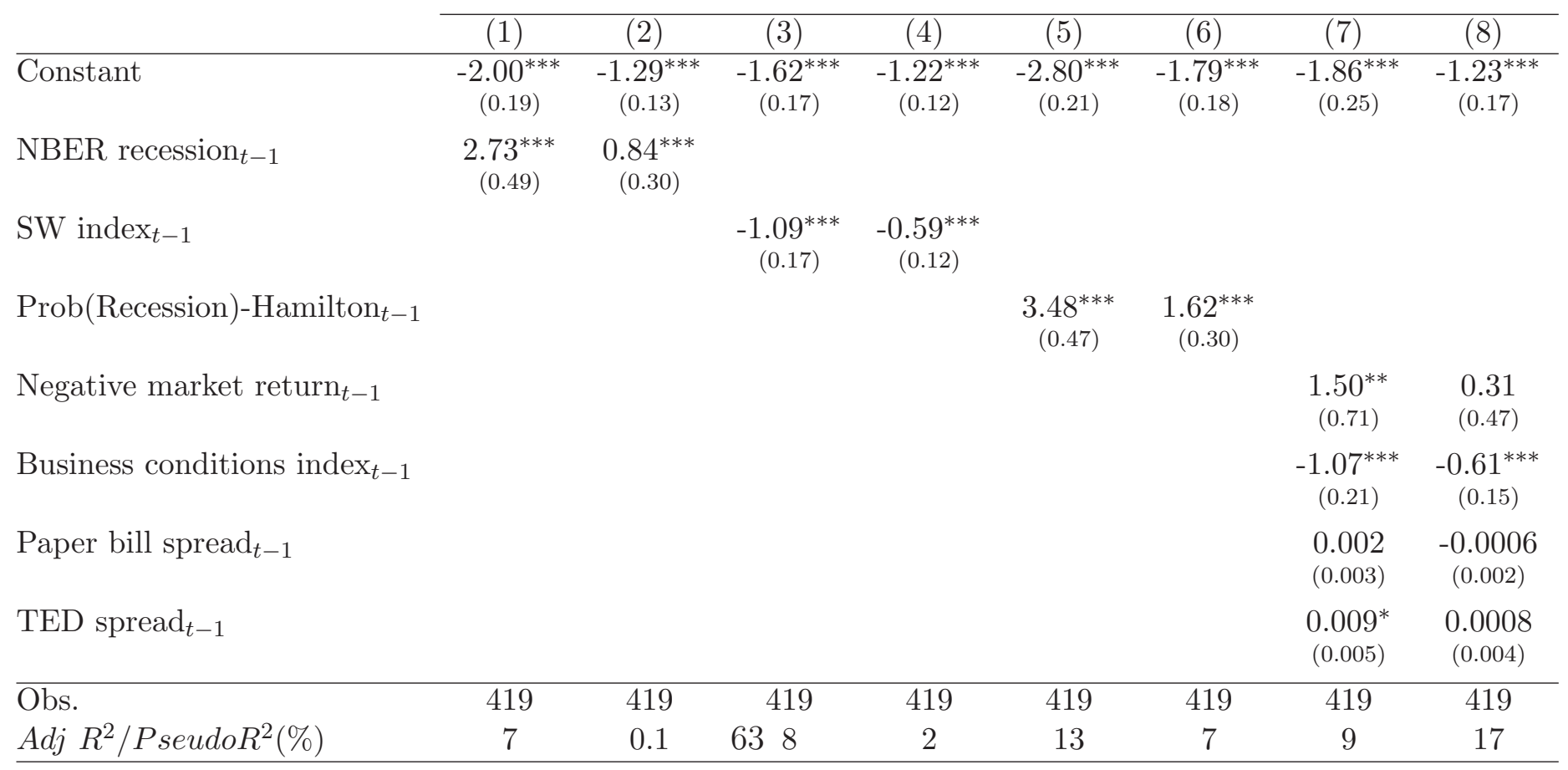









\section{Table 9}

Regime-switching model for high-minus-low book-to-market stock returns

Panel A provides the estimates of the following model.

High-minus-low book-to-market stock returns:

Regime 1: $r_{H M L B M, t}=\alpha^{1}+\beta_{H M L D E F}^{1} H M L D E F_{t}+\beta_{\text {Sit }}^{1}$ Silliq $_{t}+\beta_{\text {Bit }}^{1}$ Billiq $_{t}+\epsilon_{t}^{1}$

Regime 2: $r_{H M L B M, t}=\alpha^{2}+\beta_{H M L D E F}^{2} H M L D E F_{t}+\beta_{\text {Sit }}^{2}$ Silliq $_{t}+\beta_{B i t}^{2}$ Billiq $_{t}+\epsilon_{t}^{2}$

Markov switching probability for state transition:

$P\left(s_{t}=1 \mid s_{t-1}=1\right)=p$

$P\left(s_{t}=2 \mid s_{t-1}=2\right)=q$

In Panel B we test whether the conditional model, with the factor coefficients varying between regimes, is significantly different from the unconditional model with constant coefficients. The null hypothesis about the coefficients is $H_{0}: L \beta=c$ where $L$ is a matrix of coefficients for the hypotheses and $c$ is a vector of constants. The Wald chi-squared statistic for testing $H_{0}$ is computed as $\chi_{W}^{2}=$ $(L \hat{\beta}-c)^{\prime}\left[L \hat{V}(\hat{\beta}) L^{\prime}\right]^{-1}(L \hat{\beta}-c)$. Under $H_{0}, \chi_{W}^{2}$ has an asymptotic chi-squared distribution with $r$ degrees of freedom where $r$ is the rank of $L$ and $V$ the variance-covariance matrix of the coefficients. Low and high book-to-market stock returns is the return on the lowest and highest quintiles sorted by book-to-market ratio, and data are obtained from Ken French's data library. The variable HMLDEF is constructed as follows: Every month we classify stocks in the CRSP database in a 5 X 5 sort based on its modified $Z$-score (measure of default risk) and monthly equity volatility. Modified $Z$-score is defined as $-4.34-0.08 *$ wcta $+0.04 *$ reta- $0.1 *$ ebitta- $0.22 *$ mvliab $+0.06 *$ sata. wcta is the ratio of working capital to total assets (Compustat item (actq-lctq)/atq). reta is the ratio of retained earnings to total assets (Compustat item req/atq). ebitta is the ratio of earnings before interest and taxes to total assets (Compustat item (piq+xintq)/atq). mvliab is the ratio of market value of equity to total liabilities (Compustat item (prccq * (shoq)/ltq). sata is the ratio of sales to total assets (Compustat item saleq/atq). For each month, in each volatility quintile, we compute a market capitalization-weighted stock return for each Z-score quintile. Low default-risk stock returns then is the average of stock returns of the highest $Z$-score quintile in each volatility quintile. High default-risk stock returns then is the average of stock returns of the lowest $Z$-score quintile in each volatility quintile. HMLDEF is the difference between the High and Low default-risk stock returns. 
Panel A: Estimation of a Markov regime-switching model for HML BM (high-minus-low book-to-market)

\begin{tabular}{lcccccc}
\hline HML BM & \multicolumn{2}{c}{ Regime 1} & \multicolumn{3}{c}{ Regime 2} & \multicolumn{3}{c}{ Parameters } \\
& Coeff & $t$-Stat & Coeff & t-Stat & \\
& -4.26 & -0.25 & 64.70 & 1.67 & $p$ & 0.969 \\
Constant & 0.35 & 7.15 & 0.48 & 5.56 & $q$ & 0.935 \\
HMLDEF & 9.38 & 0.05 & -433.39 & -4.89 & & \\
Silliq & -68.73 & -1.22 & -123.81 & -0.73 & & \\
Billiq & 204.53 & & 345.87 & & & \\
$\sigma_{i}$ & & & & & &
\end{tabular}

Panel B: Wald tests for differences in coefficients between regime 1 and regime 2

HML BM

\begin{tabular}{lcc} 
& Chi-sq & $p$-Value \\
\hline Constant & 2.83 & 0.09 \\
HMLDEF & 1.00 & 0.32 \\
Silliq & 5.14 & 0.02 \\
Billiq & 0.07 & 0.79 \\
\hline
\end{tabular}

Log likelihood $\quad-2923.51$

Sample period $\quad$ 1973:01 - 2007:12 


\section{Table 10}

Flight to Liquidity Effects

Panel A presents OLS regressions of returns (or yields) of various bond (assets) portfolios on the probability of being in regime 2 (stress), obtained from the estimation in Table 3, Prob(Regime 2) ${ }^{\text {Bonds }}$, or table 7, Prob(Regime 2) ${ }^{\text {Stocks }}$, on the four bond market factors described in Table 2 and on the interaction these factors and Prob(regime 2). Columns (3)-(5) are the yields on 90-day T-bill in excess of the overnight Fed Funds effective rate (to remove policy effects). Panel B presents OLS regressions of returns (or yields) of various bond (assets) portfolios on the probability of being in regime 2 (stress), obtained from the estimation in Table 3, on the four bond market factors described in Table 2 and on the interaction of these factors and Prob(Regime 2). The returns on Junk and IG (investment-grade) are value-weighted averages of the bond portfolios in each group. The estimations in columns $3-5$ use returns on junk and IG bond portfolio groups by maturity: short-term is up to four years, medium term is between four and nine years, and long term is longer than nine years. $* * *, * * *$ Indicate significance at the $1 \%, 5 \%$, and $10 \%$ levels, respectively. Numbers in parentheses under the coefficients are standard errors.

Panel A: Flight to Liquidity Effects

\begin{tabular}{|c|c|c|c|c|}
\hline & $\begin{array}{l}\text { DEF } \\
\text { return }\end{array}$ & $\begin{array}{l}\text {-(T-bill yld } \\
\text { - Fed funds) }\end{array}$ & $\begin{array}{l}\text {-(T-bill yld } \\
\text { - Fed funds) }\end{array}$ & $\begin{array}{l}\text {-(T-bill yld } \\
\text { - Fed funds) }\end{array}$ \\
\hline & $(1)$ & $(2)$ & $(3)$ & $(4)$ \\
\hline Constant & $\begin{array}{l}6.89 \\
(4.34)\end{array}$ & $\begin{array}{c}-68.09^{* * *} \\
(4.15)\end{array}$ & $\begin{array}{c}48.57^{* * *} \\
(2.82)\end{array}$ & $\begin{array}{c}60.21^{* * *} \\
(4.17)\end{array}$ \\
\hline Prob(Regime 2) Bonds & $\begin{array}{l}-0.10 \\
(17.09)\end{array}$ & & $\begin{array}{c}50.71^{* * *} \\
(10.22)\end{array}$ & \\
\hline Prob(Regime 2) $)^{\text {Stocks }}$ & & & & $\begin{array}{c}26.22^{* *} \\
(10.91)\end{array}$ \\
\hline DEF & & $\begin{array}{c}0.07^{* *} \\
(0.03)\end{array}$ & $\begin{array}{c}-0.11^{* *} \\
(0.05)\end{array}$ & $\begin{array}{c}-0.15^{\text {*** }} \\
(0.05)\end{array}$ \\
\hline Silliq & $\begin{array}{c}-75.38^{* *} \\
(34.15)\end{array}$ & $\begin{array}{c}-25.02 \\
(20.27)\end{array}$ & $\begin{array}{l}-10.08 \\
(15.80)\end{array}$ & $\begin{array}{c}7.82 \\
(24.31)\end{array}$ \\
\hline Billiq & $\begin{array}{c}-29.67^{* *} \\
(12.11)\end{array}$ & $\begin{array}{c}-21.37^{* *} \\
(10.33)\end{array}$ & $\begin{array}{c}-7.63 \\
(7.01)\end{array}$ & $\begin{array}{c}3.36 \\
(10.40)\end{array}$ \\
\hline Prob(Regime 2$)^{\text {Bonds } *} \mathrm{DEF}$ & & & $\begin{array}{l}0.05 \\
(0.06)\end{array}$ & \\
\hline Prob(Regime 2$)^{\text {Bonds } * \text { Silliq }}$ & $\begin{array}{l}-66.43 \\
(119.28)\end{array}$ & & $\begin{array}{l}58.05 \\
(43.43)\end{array}$ & \\
\hline Prob(Regime 2) Bonds * Billiq & $\begin{array}{l}35.84 \\
(30.64)\end{array}$ & & $\begin{array}{c}57.14^{* * *} \\
(19.89)\end{array}$ & \\
\hline Prob(Regime 2$)^{\text {Stocks }} * \mathrm{DEF}$ & & & & $\begin{array}{c}0.14^{* *} \\
(0.07)\end{array}$ \\
\hline Prob(Regime 2$)^{\text {Stocks }} *$ Silliq & & & & $\begin{array}{l}37.88 \\
(38.81)\end{array}$ \\
\hline Prob(Regime 2$)^{\text {Stocks }} *$ Billiq & & & & $\begin{array}{c}45.89^{* *} \\
(20.60)\end{array}$ \\
\hline$\overline{\text { Obs. }}$ & 420 & 420 & 420 & 420 \\
\hline $\operatorname{Adj} R^{2}(\%)$ & 3 & 3 & 12 & 6 \\
\hline
\end{tabular}


Panel B: Flight to liquidity effects and bond maturity

\begin{tabular}{|c|c|c|c|c|c|}
\hline & $\begin{array}{c}\text { Junk-IG } \\
\text { Return } \\
(1)\end{array}$ & $\begin{array}{c}\text { Junk-IG } \\
\text { Return } \\
(2)\end{array}$ & $\begin{array}{c}\text { Short } \\
\text { Junk-IG } \\
(3)\end{array}$ & $\begin{array}{c}\text { Medium } \\
\text { Junk-IG } \\
(4)\end{array}$ & $\begin{array}{c}\begin{array}{c}\text { Long } \\
\text { (Junk-IG) }\end{array} \\
(5)\end{array}$ \\
\hline Const. & $\begin{array}{c}26.46^{* * *} \\
(5.96)\end{array}$ & $\begin{array}{c}26.02^{* * *} \\
(5.99)\end{array}$ & $\begin{array}{c}24.24^{* * *} \\
(5.03)\end{array}$ & $\begin{array}{c}28.43^{* * *} \\
(7.68)\end{array}$ & $\begin{array}{c}24.13^{* *} \\
(10.23)\end{array}$ \\
\hline Prob(Regime 2) & $\begin{array}{l}-2.80 \\
(22.58)\end{array}$ & $\begin{array}{r}-13.27 \\
(22.63)\end{array}$ & $\begin{array}{l}-3.50 \\
(13.00)\end{array}$ & $\begin{array}{c}-27.00 \\
(21.55)\end{array}$ & $\begin{array}{c}-13.40 \\
(25.32)\end{array}$ \\
\hline TERM & $\begin{array}{c}-0.07^{* * *} \\
(0.02)\end{array}$ & $\begin{array}{c}-0.08^{* * *} \\
(0.02)\end{array}$ & $\begin{array}{c}-0.002 \\
(0.02)\end{array}$ & $\begin{array}{c}-0.18^{* * *} \\
(0.03)\end{array}$ & $\begin{array}{c}-0.47^{* * *} \\
(0.04)\end{array}$ \\
\hline $\mathrm{DEF}$ & $\begin{array}{c}0.84^{* * *} \\
(0.12)\end{array}$ & $\begin{array}{c}0.77^{* * *} \\
(0.12)\end{array}$ & $\begin{array}{c}0.55^{* * *} \\
(0.10)\end{array}$ & $\begin{array}{c}0.61^{* * *} \\
(0.15)\end{array}$ & $\begin{array}{c}0.62^{* * *} \\
(0.16)\end{array}$ \\
\hline Silliq & & $\begin{array}{c}-64.66^{*} \\
(38.71)\end{array}$ & $\begin{array}{c}-57.79^{*} \\
(31.87)\end{array}$ & $\begin{array}{c}-64.59 \\
(52.50)\end{array}$ & $\begin{array}{c}-126.09^{*} \\
(66.66)\end{array}$ \\
\hline Billiq & & $\begin{array}{l}-2.00 \\
(12.09)\end{array}$ & $\begin{array}{c}-7.38 \\
(9.51)\end{array}$ & $\begin{array}{l}-5.81 \\
(15.82)\end{array}$ & $\begin{array}{c}-13.50 \\
(19.20)\end{array}$ \\
\hline Prob(Regime 2) $*$ TERM & $\begin{array}{l}0.04 \\
(0.10)\end{array}$ & $\begin{array}{l}0.03 \\
(0.09)\end{array}$ & $\begin{array}{l}0.01 \\
(0.05)\end{array}$ & $\begin{array}{c}-0.06 \\
(0.08)\end{array}$ & $\begin{array}{l}0.15 \\
(0.10)\end{array}$ \\
\hline Prob(Regime 2) $*$ DEF & $\begin{array}{c}-0.66^{* * *} \\
(0.22)\end{array}$ & $\begin{array}{c}-0.67^{* * *} \\
(0.20)\end{array}$ & $\begin{array}{c}-0.37^{* * *} \\
(0.14)\end{array}$ & $\begin{array}{c}-0.71^{* * *} \\
(0.22)\end{array}$ & $\begin{array}{c}-0.82^{* * *} \\
(0.24)\end{array}$ \\
\hline Prob(Regime 2) * Silliq & & $\begin{array}{c}-210.23^{*} \\
(111.17)\end{array}$ & $\begin{array}{c}-132.14^{*} \\
(76.90)\end{array}$ & $\begin{array}{c}-274.55^{* *} \\
(118.45)\end{array}$ & $\begin{array}{c}-233.20^{*} \\
(137.87)\end{array}$ \\
\hline Prob(Regime 2) * Billiq & & $\begin{array}{c}-90.79^{* *} \\
(35.79)\end{array}$ & $\begin{array}{c}-28.04 \\
(24.93)\end{array}$ & $\begin{array}{c}-76.95^{*} \\
(44.93)\end{array}$ & $\begin{array}{c}-104.61^{* *} \\
(49.71)\end{array}$ \\
\hline Obs. & 420 & 420 & 356 & 382 & 393 \\
\hline $\operatorname{Adj} R^{2}(\%)$ & 11 & 18 & 20 & 30 & 42 \\
\hline
\end{tabular}


Fig. 1.

Time-series behavior of bond returns

The figure plots in basis points the returns on corporate bonds by credit rating classes IG and junk. See definitions in Table 1 for credit rating classes. NBER recession dates are also shown as dotted lines.

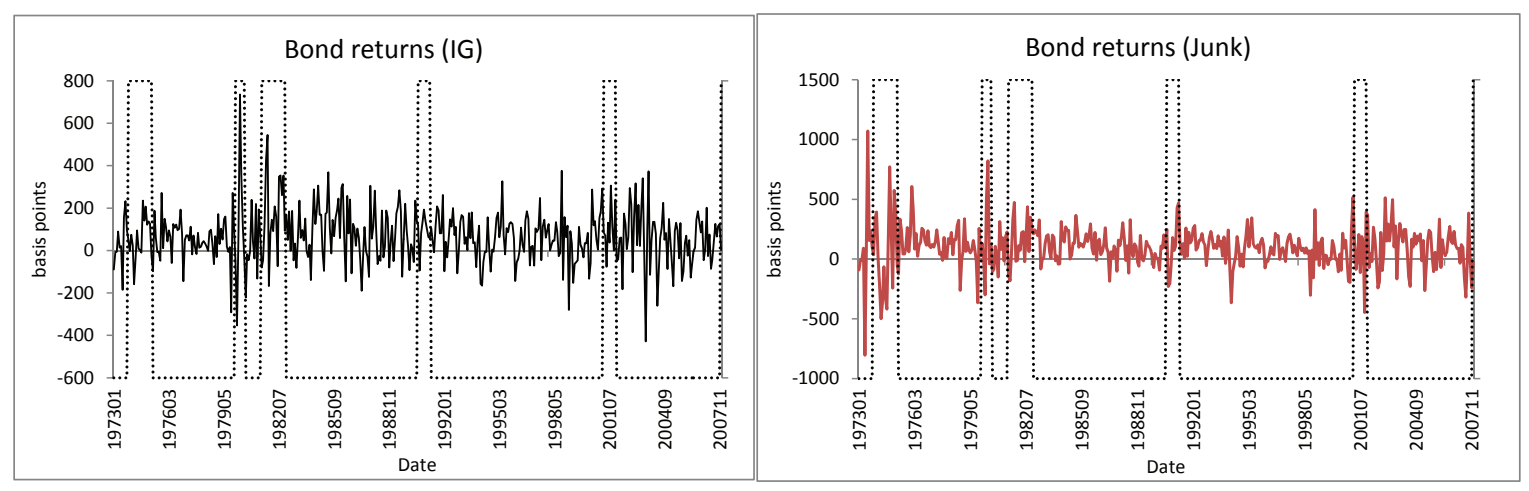


Fig. 2.

Time-series behavior of TERM and DEF bond market factors

The figure plots in basis points the bond market factors that we use: TERM (term premium), DEF (default premium). See definitions in Table 2. NBER recession dates are also shown as dotted lines.




Fig. 3.

Time Series behavior of Silliq and Billiq bond market factors

The figure plots in basis points the bond market factors that we use: Silliq (innovations on stock illiquidity), and Billiq (innovations on bond illiquidity). See definitions in Table 2. NBER recession dates are also shown as dotted lines.




Fig. 4.

Probability of high illiquidity stress regime estimated from a regime-switching model.

For details on the regime-switching model refer to Table 3 . We use the model to estimate the probability of being in regime 2 interpreted as the high illiquidity stress regime. NBER recession dates are shown.

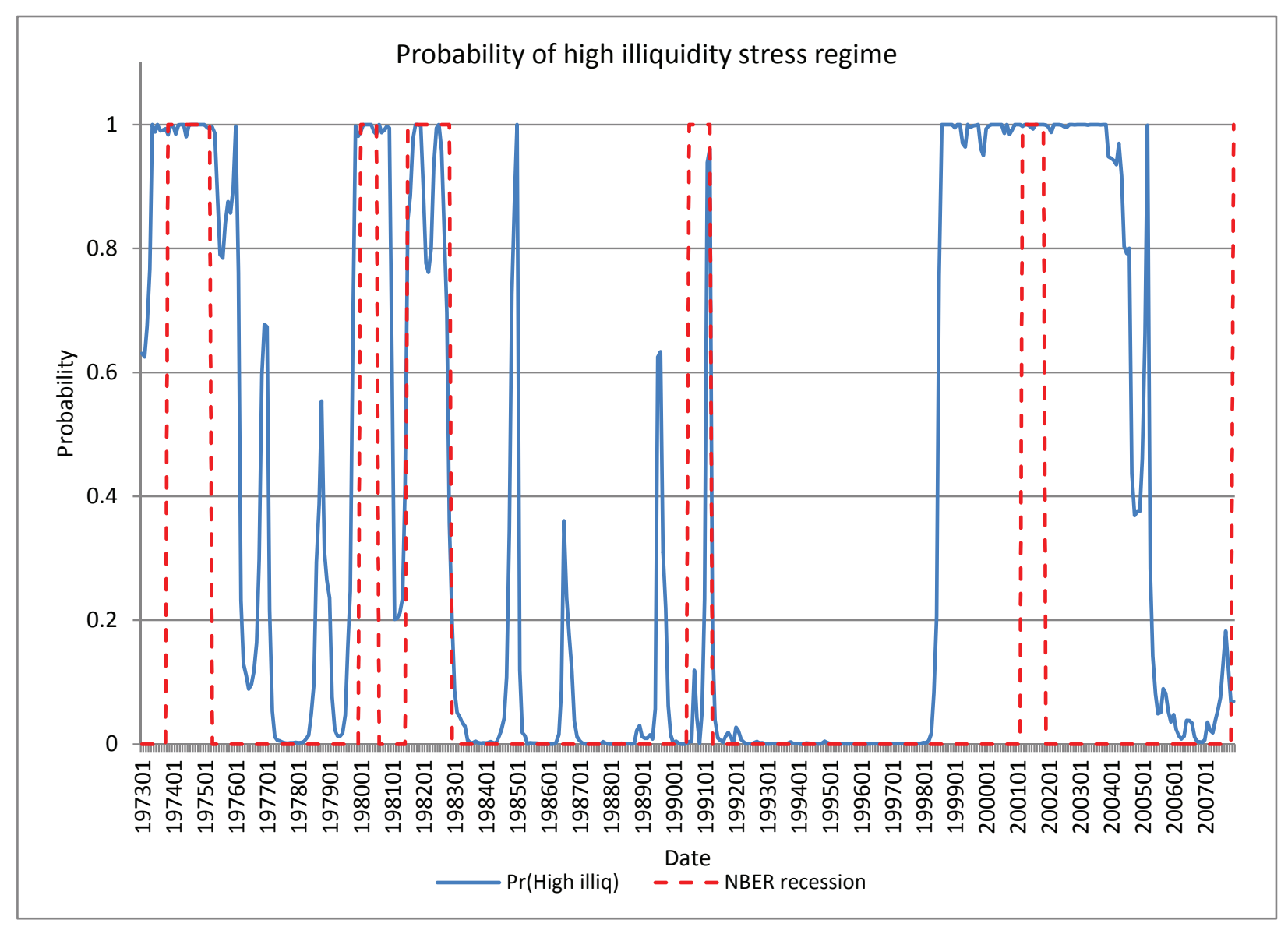


Fig. 5 .

Regime-switching model - Out-of-sample predictions during the financial crisis year 2008 and year 2009

This figure presents the regression of the actual bond returns against the predicted bond returns for the period 2008-2009. Actual returns are obtained from data on iShares investment-grade and high-yield bond index. The returns used are in excess of the 30-day T-bill return. To predict bond returns for 2008 and 2009, we proceed as follows: First, we predict the probability of regime 2 as explained in Table 6, Panel A. Next, we weight the prediction of bond returns itself for 2008-2009 from the regime-switching model of Table 3 by the respective regime probabilities to obtain the predicted bond returns (in excess of the 30-day T-bill return).
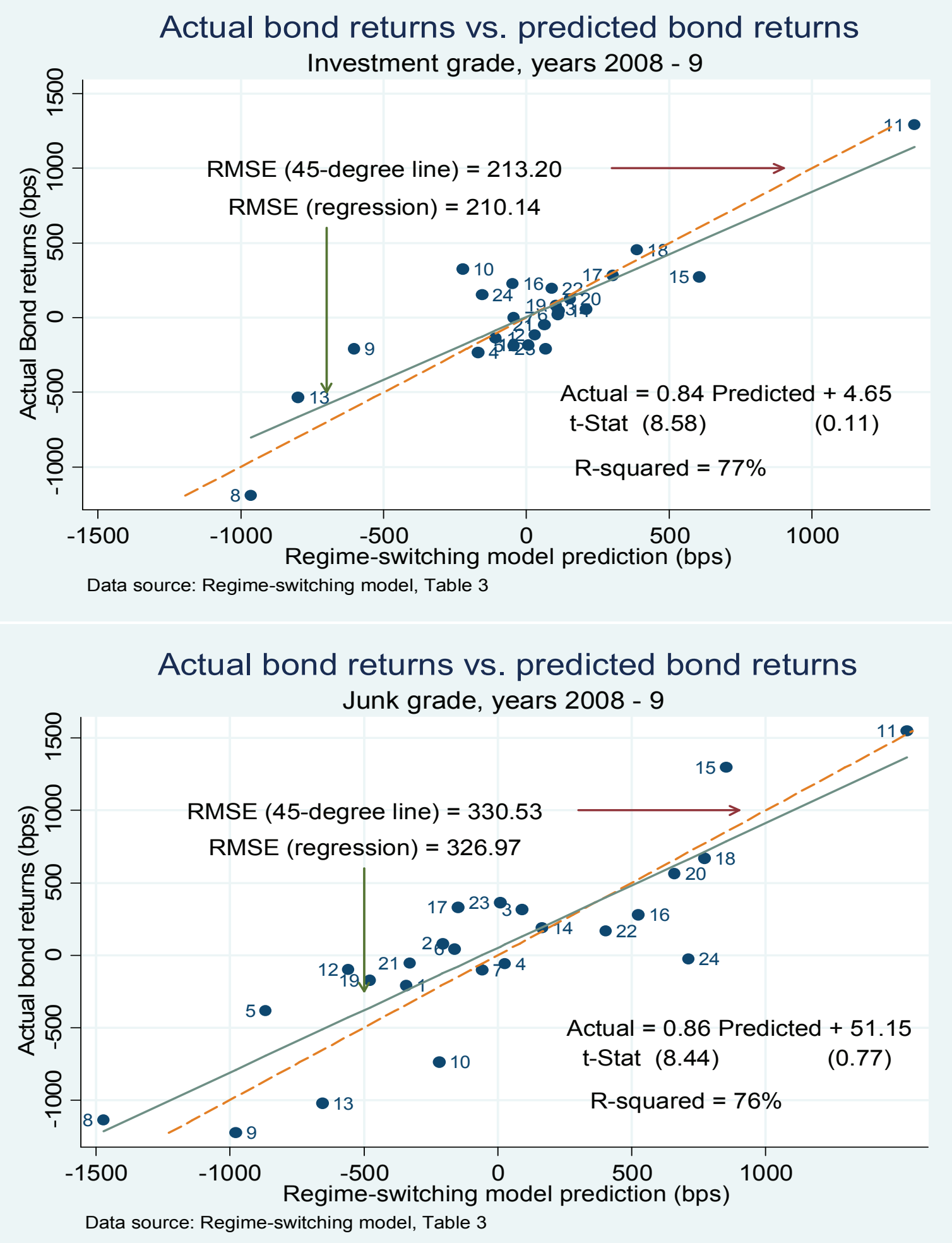
Fig. 6.

Probability of high illiquidity stress regime estimated from a regime-switching model of stock returns

For details on the regime switching model, refer to Table 7 . We use the model to estimate the probability of being in regime 2 interpreted as the high illiquidity stress regime. NBER recession dates are shown.

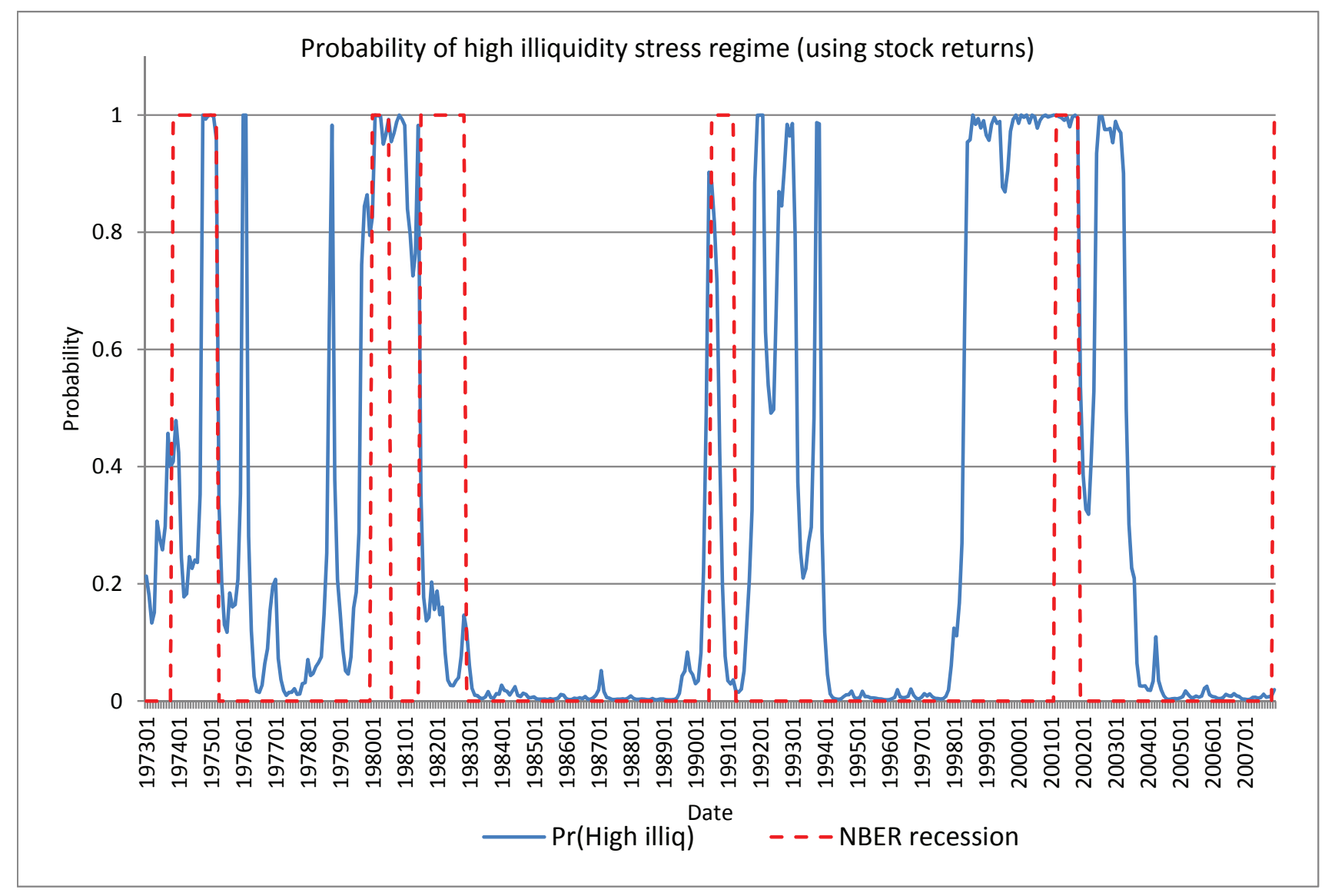

